\title{
Secondary organic aerosol production from diesel vehicle exhaust: impact of aftertreatment, fuel chemistry and driving cycle
}

\author{
T. D. Gordon ${ }^{1,2, *, * *}$, A. A. Presto ${ }^{1}$, N. T. Nguyen ${ }^{1}$, W. H. Robertson ${ }^{3}$, K. Na ${ }^{3}$, K. N. Sahay ${ }^{4}$, M. Zhang ${ }^{4}$, C. Maddox ${ }^{5}$, \\ P. Rieger ${ }^{5}$, S. Chattopadhyay ${ }^{6}$, H. Maldonado ${ }^{7}$, M. M. Maricq ${ }^{8}$, and A. L. Robinson ${ }^{1,2}$ \\ ${ }^{1}$ Center for Atmospheric Particle Studies, Carnegie Mellon University, Pittsburgh, PA 15213, USA \\ ${ }^{2}$ Engineering and Public Policy, Carnegie Mellon University, Pittsburgh, PA 15213, USA \\ ${ }^{3}$ Heavy-Duty Diesel Testing Laboratory, California Air Resources Board, Los Angeles, CA 90012, USA \\ ${ }^{4}$ Mobile Source Operations, California Air Resources Board, El Monte, CA 91731, USA \\ ${ }^{5}$ Monitoring and Laboratory, California Air Resources Board, El Monte, CA 91731, USA \\ ${ }^{6}$ Planning and Technical Support, California Air Resources Board, El Monte, CA 91731, USA \\ ${ }^{7}$ Research Division, California Air Resources Board, Sacramento, CA 95814, USA \\ ${ }^{8}$ Research and Advanced Engineering, Ford Motor Company, Dearborn, MI 48120, USA \\ *now at: National Oceanic and Atmospheric Administration Earth System Research Laboratory, Chemical Sciences Division, \\ 325 Broadway, Boulder, CO 80305, USA \\ ** now at: Cooperative Institute for Research in Environmental Sciences, University of Colorado, 216 UCB, Boulder, \\ CO 80309, USA
}

Correspondence to: A. L. Robinson (alr@andrew.cmu.edu)

Received: 19 July 2013 - Published in Atmos. Chem. Phys. Discuss.: 16 September 2013

Revised: 24 February 2014 - Accepted: 4 March 2014 - Published: 13 May 2014

\begin{abstract}
Environmental chamber ("smog chamber") experiments were conducted to investigate secondary organic aerosol (SOA) production from dilute emissions from two medium-duty diesel vehicles (MDDVs) and three heavyduty diesel vehicles (HDDVs) under urban-like conditions. Some of the vehicles were equipped with emission control aftertreatment devices, including diesel particulate filters (DPFs), selective catalytic reduction (SCR) and diesel oxidation catalysts (DOCs). Experiments were also performed with different fuels (100\% biodiesel and low-, mediumor high-aromatic ultralow sulfur diesel) and driving cycles (Unified Cycle, Urban Dynamometer Driving Schedule, and creep + idle). During normal operation, vehicles with a catalyzed DPF emitted very little primary particulate matter (PM). Furthermore, photooxidation of dilute emissions from these vehicles produced essentially no SOA (below detection limit). However, significant primary PM emissions and SOA production were measured during active DPF regeneration experiments. Nevertheless, under reasonable assumptions about DPF regeneration frequency, the contribution of regeneration emissions to the total vehicle emissions is neg-
\end{abstract}

ligible, reducing PM trapping efficiency by less than $2 \%$. Therefore, catalyzed DPFs appear to be very effective in reducing both primary PM emissions and SOA production from diesel vehicles. For both MDDVs and HDDVs without aftertreatment substantial SOA formed in the smog chamber - with the emissions from some vehicles generating twice as much SOA as primary organic aerosol after $3 \mathrm{~h}$ of oxidation at typical urban $\mathrm{VOC} / \mathrm{NO}_{\mathrm{x}}$ ratios $(3: 1)$. Comprehensive organic gas speciation was performed on these emissions, but less than half of the measured SOA could be explained by traditional (speciated) SOA precursors. The remainder presumably originates from the large fraction $(\sim 30 \%)$ of the nonmethane organic gas emissions that could not be speciated using traditional one-dimensional gas chromatography. The unspeciated organics - likely comprising less volatile species such as intermediate volatility organic compounds - appear to be important SOA precursors; we estimate that the effective SOA yield (defined as the ratio of SOA mass to reacted precursor mass) was $9 \pm 6 \%$ if both speciated SOA precursors and unspeciated organics are included in the analysis. SOA production from creep + idle operation was 3-4 times 
larger than SOA production from the same vehicle operated over the Urban Dynamometer Driving Schedule (UDDS). Fuel properties had little or no effect on primary PM emissions or SOA formation.

\section{Introduction}

Numerous studies have shown that organic aerosol is a major component of atmospheric fine particulate matter $\left(\mathrm{PM}_{2.5}\right)$ (Kanakidou et al., 2005) and that secondary organic aerosol (SOA) - formed in the atmosphere from the oxidation of organic vapors - often exceeds the organic aerosol directly emitted from sources (primary organic aerosol, or POA), even in urban areas (Jimenez et al., 2009; Subramanian et al., 2007; Stone et al., 2009). Diesel vehicles are an important source of organic aerosol and SOA precursors, especially in urban areas. However, the overall contribution of these emissions to ambient $\mathrm{PM}_{2.5}$ concentrations is uncertain (Bahreini et al., 2012; Gentner et al., 2012).

SOA production from diesel emissions is a relatively new area of research, but there is evidence that it may be an important organic aerosol source (Chirico et al., 2010; Miracolo et al., 2010; Samy and Zielinska, 2010; Weitkamp et al., 2007; Gentner et al., 2012). Robinson et al. (2007) reported substantial SOA production from a small diesel generator. Chirico et al. (2010) found that emissions from a mediumduty diesel vehicle (MDDV) produced substantial SOA mass relative to black carbon $\left(\mathrm{BC}\right.$; roughly $\left.0.4 \leq \frac{\mathrm{SOA}}{\mathrm{BC}} \leq 1.0\right)$ and $\mathrm{POA}\left(\frac{\mathrm{SOA}}{\mathrm{POA}} \cong 3.1\right)$ after $5 \mathrm{~h}$ of photooxidation.

The US Environmental Protection Agency (EPA) implemented strict new PM emission standards in 2007 for diesel vehicles, and similar standards were adopted in the European Union (2009 for light-duty and 2013 for heavy-duty). These standards effectively required the use of diesel particulate filters (DPFs). In addition, in 2010 new US $\mathrm{NO}_{\mathrm{x}}$ standards effectively required implementation of aftertreatment (AT) technologies such as selective catalytic reduction (SCR). The effect of these new control technologies on SOA formation is not well understood. Chirico et al. (2010) report that, although primary PM emissions remained unaffected, SOA production was reduced by more than a factor of 20 for light-duty diesel vehicles equipped with a diesel oxidation catalyst (DOC). This result is consistent with the welldocumented reduction in SOA precursors caused by DOCs (Liu et al., 2008, 2010; Samy and Zielinska, 2010). However, Chirico et al. (2010) did not test the vehicles over realistic driving cycles.

Although aftertreatment technologies have been shown to be highly effective in reducing primary emissions, higheremissions may occur during DPF regeneration (when the accumulated soot is burned off the DPF). During active DPF regeneration, fuel is injected upstream of the DPF, and its combustion generates sufficient heat to oxidize the trapped soot.
During regeneration both the PM mass and number concentration can increase by orders of magnitude (Khalek et al., 2011). Furthermore, even during normal (nonregeneration) operation, DPFs can emit unexpectedly high concentrations of nucleation mode particles (primarily sulfate) (Herner et al., 2011).

Given their long lifespan, older, higher emitting diesel vehicles without aftertreatment devices are likely to constitute a significant fraction of the heavy-duty diesel vehicle (HDDV) fleet for the next decade in the United States, and longer in other parts of the world. Therefore, it would be advantageous if fuels could be reformulated to reduce emissions. Miracolo et al. (2012) demonstrated that switching from petroleum-based fuel to Fischer-Tropsch fuel dramatically reduced SOA formation from dilute emissions from a gas turbine engine. Extensive gasoline reformulation in the 1990s (and earlier) in the United States reduced ambient ozone, $\mathrm{NO}_{\mathrm{x}}$, carbon monoxide and air toxics concentrations (Anderson and Rykowski, 1997). Odum et al. (1997) showed that reducing the aromatic content of gasoline reduced the SOA formed when evaporated fuel was photooxidized, suggesting that fuel reformulation could be an effective strategy for reducing SOA precursors from tailpipe emissions. However, combustion emissions are far more complex than vaporized fuel; thus, the latter may not be a good surrogate for the former in estimating SOA production.

In this paper, we present data from smog chamber experiments investigating the SOA formation from dilute emissions from two medium-duty and three heavy-duty diesel vehicles that were equipped with different aftertreatment technologies, including DPFs and SCRs. The vehicles were operated on a chassis dynamometer over standard driving cycles using different fuels (including diesels with a range of aromatic content and $100 \%$ biodiesel). We also characterized the primary emissions and secondary PM production resulting from active DPF regeneration. Finally, comprehensive speciation of the gas-phase emissions was performed to evaluate their SOA formation potential. This research was conducted as part of a larger project investigating the link between tailpipe emissions from mobile sources and ambient PM. Companion papers summarize (1) the primary emissions data (May et al., 2014), (2) the gas-particle partitioning of POA emissions (May et al., 2013a, b), (3) the SOA formation from on-road gasoline vehicles (Gordon et al., 2013a), and (4) the SOA formation from small off-road engines (Gordon et al., 2013b).

\section{Materials and methods}

\subsection{Vehicles}

Table 1 lists the five diesel vehicles tested during this study. Although this is a small fleet, the vehicles span a range of emission control technologies. The three heavyduty diesel vehicles were equipped with six-cylinder, inline, 
Table 1. MDDV experiments were conducted at the California Air Resources Board (CARB) Haagen-Smit Laboratory; the HDDV experiments were conducted at the CARB Heavy Duty Vehicle Laboratory (Herner et al., 2009; Pisano et al., 2011). The experimental setup and procedures are essentially the same as those used for other vehicle testing by our group (Gordon et al., 2013a). A schematic of the experimental setup is shown in Fig. 1a. The experimental design - including all combinations of vehicles, fuels, aftertreatment (AT) and driving cycles - is provided in Fig. $1 b$.

\begin{tabular}{rcccrrr}
\hline & Vehicle ID & Emissions controls & Model year & Eng. size (L) & Mileage & Avg. mpg \\
\hline \multirow{3}{*}{ HDDV } & D1 & DOC + DPF + SCR & 2010 & 14.9 & 11000 & 4.5 \\
& D2 & DOC + DPF & 2007 & 12.8 & 22000 & 4.9 \\
\hline \multirow{4}{*}{ MDDV } & D3 & none & 2006 & 10.8 & 94000 & 4.3 \\
& D4 & DOC & 2005 & 6.6 & 66000 & 11.8 \\
& D5 & none & 2001 & 5.9 & 159000 & 13.7 \\
\hline
\end{tabular}

direct-injection, turbocharged, heavy-duty diesel engines. The 2006 HDDV (D3) had no exhaust aftertreatment. The 2007 HDDV (D2) had an original equipment manufacturer (OEM)-installed catalyzed DPF. The 2010 HDDV (D1) was equipped with an OEM-installed catalyzed DPF with a SCR system. The two MDDVs were full-sized pickup trucks with gross vehicle weight ratings between 8500 and $9500 \mathrm{lbs}$ (3900-4300 kg). The 2005 MDDV (D4) had a turbocharged V8 engine equipped with a DOC. The 2001 MDDV (D5) had a turbocharged inline six-cylinder engine with no aftertreatment. The experiment naming convention is the vehicle ID followed by the experiment number. For example, "D5.3" refers to the third experiment with vehicle 5 .

\subsection{Fuels}

The HDDVs were tested with three different ultralow sulfur diesel (ULSD) fuels: low aromatic (9\% aromatic content), mid-aromatic (12\% aromatic content) and high aromatic (28\% aromatic content). Both of the MDDVs were tested with a commercial ULSD purchased from a local gas station, which was similar but not identical to the mid-aromatic ULSD used in the HDDV experiments. The 2001 MDDV (D5) was also tested on B100 soy-based biodiesel. Results from fuel analyses are in the Supplement.

During the HDDV experiments fuel was supplied from external tanks to simplify fuel switching. After a fuel switch, an active regeneration was performed on the two DPF-equipped HDDVs. During fuel changes with non-DPF-equipped HDDVs, the recirculating fuel system was rinsed with five gallons of the new fuel while the engine idled, followed by $20 \mathrm{~min}$ of high-speed driving. When the $2001 \mathrm{MDDV}$ was switched from ULSD to biodiesel, the vehicle's fuel tank was drained and filled with biodiesel and driven for $\sim 1 \mathrm{~h}$ at 50 $60 \mathrm{mph}$ prior to testing.

\subsection{Driving cycles}

Speed traces for the test cycles used in this study are plotted in Fig. S3 in the Supplement. The MDDVs were tested using the cold-start Unified Cycle (UC), which was designed to simulate urban driving in the Los Angeles area (California Air Resources Board, 1996). The majority of the HDDV experiments were conducted using the Urban Dynamometer Driving Schedule (UDDS), which represents urban operation of HDDVs (Lammert et al., 2012). Following a 20 min warmup ( $10 \mathrm{~min}$ of driving at $50 \mathrm{mph}$ and a $10 \mathrm{~min}$ hot soak), the UDDS was run two times in immediate succession with no hot-soak period between the cycles, and emissions were collected over the entire $35.4 \mathrm{~min}$ double UDDS cycle. One test with the non-DPF-equipped HDDV was performed using a portion of the Heavy Heavy-Duty Diesel Truck (HHDDT) driving schedule (Zhen et al., 2009). In experiment D3.5 the creep phase of the four-phase HHDDT cycle (251 s) was run three times in immediate succession followed by $1800 \mathrm{~s}$ of idling (we refer to this as the creep + idle cycle). The emissions from the two DPF-equipped HDDVs (D1 and D2) were also characterized during stationary, active regeneration during which the engine control system injects fuel upstream of the DPF to induce combustion of the PM deposited in the filter.

\subsection{Experimental setup}

The MDDVs were driven on a Clayton (Model AC-48) 48 inch $(1.22 \mathrm{~m})$ single-roll electric chassis dynamometer, and the HDDVs were driven on a Schenck Pegasus chassis dynamometer. The HDDVs were tested with a nominal inertial load of 56000 pounds $(250 \mathrm{kN})$. The entire exhaust was sampled using a Horiba constant volume sampling (CVS) system, and samples were collected from the CVS to characterize the primary emissions. The primary PM mass emissions were measured gravimetrically using Teflon ${ }^{\circledR}$ filters nominally following the CFR 1065 procedures (CFR, 2008). Carbonaceous aerosol emissions were characterized using quartz-fiber filters analyzed with a Sunset Laboratory Organic Carbon/Elemental Carbon (OC/EC) Analyzer using 

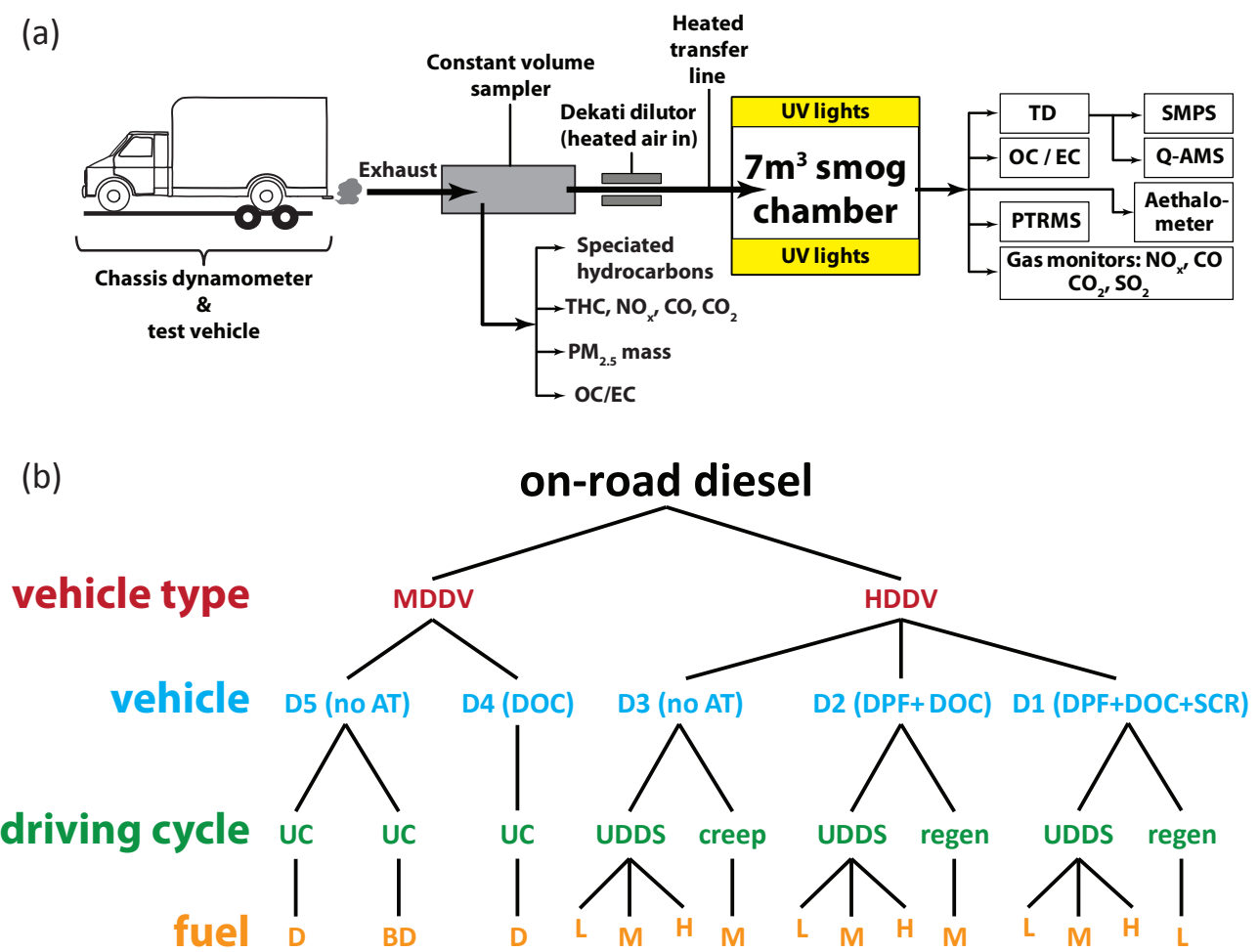

Fig. 1. (a) Test setup used to characterize the primary emissions and to photooxidize them (not to scale). TD=thermodenuder, OC/EC = organic/elemental carbon analyzer, PTRMS = proton transfer reaction mass spectrometer, SMPS = scanning mobility particle sizer, $\mathrm{Q}-\mathrm{AMS}$ = quadrupole aerosol mass spectrometer. (b) Experimental design matrix of all tested combinations of vehicles (D1 through D5, Table 1) with different aftertreatment systems (no AT $=$ no exhaust aftertreatment, $\mathrm{DOC}=$ diesel oxidation catalyst, $\mathrm{DPF}+\mathrm{DOC}=\mathrm{catalyzed}$ diesel particulate filter, DPF + DOC + SCR = catalyzed diesel particulate filter + selective catalytic reduction), driving cycles $(\mathrm{UC}=\mathrm{Unified}$ Cycle, UDDS = Urban Dynamometer Driving Schedule, creep + idle, active regeneration) and fuels $(\mathrm{D}=\mathrm{commercial}$ ULSD, $\mathrm{BD}=100 \%$ biodiesel, and L=low-, $\mathrm{M}=$ medium-, and $\mathrm{H}=$ high-aromatic ULSD). Duplicate experiments are not shown.

the IMPROVE protocol (Chow et al., 1993). Samples from the CVS were collected in heated Tedlar $^{\circledR}$ bags and analyzed offline for total hydrocarbons, methane, light hydrocarbons $\left(<\mathrm{C}_{5}\right)$ and mid-weight hydrocarbons $\left(\mathrm{C}_{5}\right.$ to $\left.\mathrm{C}_{12}\right)$ using standard analytical procedures (California Air Resources Board, 2001, 2004, 2006). Carbonyl emissions were determined from 1,4-dinitrophenylhydrazine (DNPH)-impregnated cartridges analyzed by high-performance liquid chromatography. For the MDDV, emissions of 202 organic species were quantified. A different analysis protocol was used for the HDDV samples, which quantified the emissions of only 49 species. A complete list of organic species is provided in Table S4. Organic mass that eluted from the gas chromatograph that could not be individually identified were binned according to Kovats index (elution time). Unspeciated nonmethane organic gases (NMOG) with Kovats indices $\geq 800$ (i.e., noctane) were assumed to be SOA precursors; NMOG with Kovats indices $<800$ were assumed not to be SOA precursors.

A slipstream of the dilute emissions from the CVS were transferred via a 0.5 -in-outer-diameter (o.d.) $\times 12 \mathrm{~m}$-long heated $\left(47^{\circ} \mathrm{C}\right)$ Silcosteel ${ }^{\circledR}$ (i.e., passivated internal bore) tube into a $7 \mathrm{~m}^{3}$ Teflon ${ }^{\circledR}$ smog chamber (Hennigan et al., 2011). Before each experiment the chamber was cleaned by flushing with high-efficiency particulate air (HEPA)and activated-carbon-filtered air overnight. Vehicle emissions were added to a partially filled chamber over the entire driving cycle; thus, these experiments represent trip average emissions. The exhaust was diluted in three stages: first, it was diluted about 10:1 with ambient-temperature HEPAand activated-carbon-filtered air in the CVS; it was then diluted about $8: 1$ with $47{ }^{\circ} \mathrm{C}$ HEPA- and activated-carbonfiltered air using Dekati ejector diluters in the transfer line; finally, it was diluted about $2: 1$ with ambient temperature HEPA- and activated-carbon-filtered air in the smog chamber.

For experiments with the DPF-equipped vehicles, approximately $10 \mu \mathrm{g} \mathrm{m}^{-3}$ of ammonium sulfate seed aerosol was injected into the chamber just before the vehicle was started. No seed aerosol was added with the non-DPF-equipped vehicles because of their high primary PM emissions. After adding exhaust, nitrous acid (HONO) was bubbled into the chamber as a hydroxyl radical $(\mathrm{OH})$ source, and $\mathrm{VOC} / \mathrm{NO}_{\mathrm{x}}$ ratios were adjusted to approximately $3: 1$ (typical of many 
urban environments; Fujita et al., 2002) by adding propene (which does not form SOA; Kroll and Seinfeld, 2008): 2.9$3.8 \mathrm{ppm}$ for HDDVs and 0.7-4.1 ppm for MDDVs. Propene is commonly added in chamber experiments to support oxidation by rebalancing the direct sinks of $\mathrm{OH}$ radicals in favor of organics rather than $\mathrm{NO}_{2}$. Propene also increases the steady-state level of peroxy radicals. Since the HDDV and MDDV experiments were performed at two different facilities in different locations, the light source for the MDDV experiments was different than for the HDDV experiments. After $\sim 45$ min characterizing the primary emissions in a dark chamber, the MDDV emissions were photooxidized for $3 \mathrm{~h}$ by exposing them to UV lights (Model F40BL UVA, General Electric), whereas the HDDV emissions were photooxidized for $3 \mathrm{~h}$ by direct exposure to sunlight. The $\mathrm{NO}_{2}$ photolysis rate in the chamber during the MDDV experiments was approximately $0.16 \mathrm{~min}^{-1}$, and the spectral characteristics of the UV lamps (maximum output was at $\sim 350 \mathrm{~nm}$ ) are described elsewhere (Presto et al., 2005b).

While the different light sources in the MDDV and HDDV experiments could introduce some uncertainty, this is not expected to significantly impact our conclusions for at least three reasons. First, as pointed out by Platt et al. (2013), the emission fingerprint of the UV lamps as a function of wavelength and temperature overlaps with the absorption cross section for the photolysis of $\mathrm{OH}, \mathrm{O}_{3}$, and $\mathrm{HONO}$ (Carter et al., 1995). Therefore, despite differences in emission intensity between UV lights and sunlight, UV lights are a good sunlight surrogate. Second, the primary conclusions of this paper are based on the HDDV experiments; thus, any variability in SOA production due to the different light sources for the MDDV experiments should not alter the main findings. Finally, similar SOA production rates were measured for the different non-DPF-equipped vehicles regardless of light source.

An array of instruments was used to characterize gasand particulate-phase pollutants inside the chamber. Particle number distributions were measured with a scanning mobility particle sizer (SMPS, TSI, Inc., classifier model 3080, CPC model 3772). Nonrefractory submicron aerosol mass and chemical composition were measured with a quadrupole aerosol mass spectrometer (AMS, Aerodyne, Inc.). Gasphase organic species were measured with a proton transfer reaction mass spectrometer (PTR-MS, Ionicon) operated in selected-ion mode with a time resolution of $\sim 2.5 \mathrm{~min}$. The PTR-MS was calibrated daily using a custom gas standard from Spectra Gases. Gas monitors were used to measure $\mathrm{CO}_{2}$ (LI-820, Li-Cor Biosciences), $\mathrm{SO}_{2}, \mathrm{NO}_{\mathrm{x}}, \mathrm{CO}$, and $\mathrm{O}_{3}$ (API-Teledyne Models 100E, 200A, 300A and 400E); these monitors were zeroed daily and calibrated at least weekly. BC emissions were measured with a single particle soot photometer (SP2, DMT, Inc.) and a seven channel Aethalometer ${ }^{\circledR}$ (Magee Scientific, Model AE-31). The Aethalometer ${ }^{\circledR}$ data were corrected for particle loading effects using the method of Kirchstetter and Novakov (2007).
During the MDDV testing the smog chamber was located indoors, in a large air-conditioned space; its temperature and humidity varied within the ranges of $25-30{ }^{\circ} \mathrm{C}$ and $30-50 \%$. During the HDDV testing the smog chamber was located outside; temperature and humidity in the chamber varied within the ranges of $19-38^{\circ} \mathrm{C}$ and $9-51 \%$. The quoted temperature and humidity ranges describe the variability between different experiments.

SOA formation is complex and depends on many factors, including precursor concentrations, PM concentration, oxidant exposure, and oxidation conditions (e.g., $\mathrm{VOC} / \mathrm{NO}_{\mathrm{x}}$ ) (Hallquist et al., 2009). Given this complexity we attempted to simulate urban conditions inside the chamber, focusing our attention on variables known to strongly influence SOA formation ( $\mathrm{PM}$ concentrations and $\mathrm{VOC} / \mathrm{NO}_{\mathrm{x}}$ ). Initial concentrations for select pollutants (NO, $\mathrm{NO}_{2}, \Delta \mathrm{CO}_{2}$, etc.) for all the chamber experiments (including a dynamic blank experiment) are listed in Table S3 in the Supplement. Measurements of EC, POA, primary PM and CO in the CVS and SOA after $3 \mathrm{~h}$ of photooxidation are provided in Table S5 in the Supplement. Initial PM concentrations ranged from 34 to $56 \mu \mathrm{g} \mathrm{m}^{-3}$ for D3 operated on the UDDS (the creep + idle tests had much lower concentrations) and from 19 to $71 \mu \mathrm{g} \mathrm{m}^{-3}$ for the MDDVs. The mixing ratios of individual single-ring aromatics in the chamber were typically less than $1 \mathrm{ppb}$. However, initial $\mathrm{NO}_{\mathrm{x}}$ concentrations were between 0.4 and $2.4 \mathrm{ppm}$ for non-SCR-equipped vehicles and $\sim 0.2 \mathrm{ppm}$ for the HDDV with the SCR. This is much higher than typical atmospheric conditions and, in some experiments, required the addition of substantial amounts of propene (Table S3) to achieve the target $\mathrm{VOC} / \mathrm{NO}_{\mathrm{x}}$ of $\sim 3: 1 \mathrm{ppbC} \mathrm{ppb}^{-1} \mathrm{NO}_{\mathrm{x}}$. In addition, the mix of organics inside the chamber (diesel exhaust + propene) is different than a typical urban mix. While the chamber experiment can never exactly reproduce urban conditions, these measures help ensure that the important radical branching channels such as the fate of organoperoxy radicals $\left(\mathrm{RO}_{2}\right)$ are similar to those in the atmosphere (Presto et al., 2005a; Lim and Ziemann, 2009; Ng et al., 2007).

\subsection{Data analysis}

Pollutant data are reported per mass of fuel burned (mg pollutant $\mathrm{kg}$-fuel ${ }^{-1}$ ):

$\mathrm{EF}=\frac{[P]}{\left[\mathrm{CO}_{2}\right]} \cdot \frac{\mathrm{MW}_{\mathrm{CO}_{2}}}{\mathrm{MW}_{\mathrm{C}}} \cdot C_{\mathrm{f}}$,

where $[P]$ is the background corrected pollutant concentration in $\mu \mathrm{g} \mathrm{m}^{-3},\left[\mathrm{CO}_{2}\right]$ is the background corrected concentration of $\mathrm{CO}_{2}$ in the chamber in $\mu \mathrm{g} \mathrm{m}^{-3}, \mathrm{MW}_{\mathrm{CO}_{2}}$ is the molecular weight of $\mathrm{CO}_{2}\left(44.1 \mathrm{~g} \mathrm{~mol}^{-1}\right), \mathrm{MW}_{\mathrm{C}}$ is the molecular weight of carbon $\left(12 \mathrm{~g} \mathrm{~mol}^{-1}\right)$ and $C_{\mathrm{f}}$ is the carbon intensity of the fuel determined from fuel analyses $(0.85 \mathrm{~kg} \mathrm{C} \mathrm{kg}$ fuel $^{-1}$ for diesel, $0.77 \mathrm{~kg} \mathrm{C} \mathrm{kg-fuel}{ }^{-1}$ for biodiesel). Equation (1) assumes that all carbon in the fuel is converted to $\mathrm{CO}_{2}$. This assumption was verified with the $\mathrm{CO}$ and NMOG 
data; for example, the $\mathrm{CO} / \mathrm{CO}_{2}$ ratios for MDDV and $\mathrm{HDDV}$ were less than 0.005 .

Hydroxyl radical $(\mathrm{OH})$ levels in the chamber were inferred from the decay of VOCs (e.g., toluene, xylenes, TMB, propene) measured with the PTR-MS (Atkinson and Arey, 2003). Typical experiment average $\mathrm{OH}$ levels were $5 \times 10^{6}$ molecules $\mathrm{cm}^{-3}$, which is within the range of summer daytime atmospheric concentrations (Seinfeld and Pandis, 2006). OH levels were generally higher (2$3 \times 10^{7}$ molecules $\mathrm{cm}^{-3}$ ) during the beginning of the photooxidation phase of the experiment and then fell as the HONO was photolyzed.

The fragmentation table from Allan et al. (2004) was used to interpret the AMS data. The contribution of gas-phase $\mathrm{CO}_{2}$ to the AMS $m / z \quad 44$ signal was corrected using the measured $\mathrm{CO}_{2}$ concentrations. There was no evidence of organic particle signal at $m / z 28\left(\mathrm{CO}^{+}\right)$. Using the approach of Farmer et al. (2010), only a minor fraction (typically $<5 \%$ ) of the nitrate mass (which was usually quite small) was attributable to organics.

To quantify SOA production in the smog chamber the AMS and SMPS data were corrected for the loss of particles and vapors to the chamber walls. Details of this correction are contained in the Supplement. Briefly, the loss of organic particles to the walls is well constrained. It is treated as a first-order process (McMurry and Grosjean, 1985) with a rate constant determined from the measured decay of an inert tracer species (BC or sulfate seed). The particle wall-loss rate constant ranged from 0.46 to $0.66 \mathrm{~h}^{-1}$. Wall-loss rate constants calculated from the Aethalometer ${ }^{\circledR}$ and the SP2 were within $4 \%(n=8)$, indicating that the Aethalometer ${ }^{\circledR}$ measurements were not influenced by SOA formation.

Using BC or sulfate as a tracer for particle wall loss requires the assumption that the aerosol is internally mixed. This assumption was valid for most experiments because the size-resolved data (SMPS and AMS) only showed growth of the primary-mode aerosol. However, the majority of particle mass in the two regeneration experiments was formed from nucleation, which requires correcting the wall-loss rate to account for the more rapid loss of smaller nucleation mode particles. This correction is discussed in the SI. In several of the MDDV experiments the sum of the AMS measured nonrefractory components and BC was significantly lower than the mass calculated from the SMPS size distributions. Such deviations are likely due to differences in AMS collection efficiency and are corrected as described in the Supplement. These differences do not affect the conclusions of the paper.

The loss of condensable organic vapors to wall-bound particles was estimated by considering two cases (Weitkamp et al., 2007). A lower bound estimate assumes no loss of vapors to the chamber walls - i.e., that the mass transfer resistance to the walls is much greater than to the suspended particles. It is equivalent to the " $\omega=0$ " correction utilized in previous studies (Weitkamp et al., 2007; Miracolo et al., 2011). The second estimate assumes that the particles lost to the walls remain in equilibrium with the vapor phase (" $\omega=1$ " correction; Weitkamp et al., 2007); therefore, the loss of organic vapors scales with the ratio of mass of particles on the walls to particles in suspension. The two vapor loss estimates diverge as more particles are lost to the wall, increasing the uncertainty in the wall-loss-corrected SOA mass as an experiment progresses (Hildebrandt et al., 2009). We imposed a $5: 1$ upper bound on the ratio of OA on the wall to suspended OA. This condition was binding in roughly half the experiments, typically only later in the experiment after $1.5-2.5 \mathrm{~h}$ of photooxidation. We do not consider the loss of organic vapors directly to the chamber walls (in distinction to their loss to wall-bound particles) (Matsunaga and Ziemann, 2010). This is highly uncertain; if included, it would increase our estimated SOA production.

Chamber dynamic blank experiments were performed after filling the chamber with CVS dilution air (but no vehicle exhaust), HONO, propene and ammonium sulfate seed particles. These experiments produced $1-3 \mu \mathrm{g} \mathrm{m}^{-3}$ of SOA over a $3 \mathrm{~h}$ photooxidation period. This SOA is likely formed from the residual vapors that desorb from the CVS, transfer line and chamber walls. Therefore, for every chamber experiment we assume an SOA blank of $0 \mu \mathrm{g} \mathrm{m}^{-3}$ at time $(t)=0$ that increases linearly to $2 \mu \mathrm{g} \mathrm{m}^{-3}$ of SOA at $t=3 \mathrm{~h}$ and subtract this artifact from the reported SOA production.

\section{Results and discussion}

Figure 2 illustrates the temporal evolution of both particleand gas-phase species during a typical smog chamber experiment (experiment D3.13). There are three distinct periods in each experiment. First, vehicle emissions are added to the chamber throughout the entire driving cycle (the $35 \mathrm{~min}$ $2 \times$ UDDS is shown here), increasing the concentrations of VOCs, $\mathrm{CO}_{2}$ and $\mathrm{NO}_{\mathrm{x}}$. The second period begins when the engine was shut off at $t=-2 \mathrm{~h}$. The primary emissions were characterized during this period. HONO was added to the chamber at approximately $t=-0.5 \mathrm{~h}$, leading to a modest increase in $\mathrm{NO}_{2}$ concentration. Propene was also added at this time to adjust the $\mathrm{VOC} / \mathrm{NO}_{\mathrm{x}}$ ratio to approximately 3 . The third period begins when the UV lights were turned on (MDDV) or the chamber was exposed to sunlight (HDDV). SOA was quickly generated at the beginning of this period; while the wall-loss-corrected black carbon concentration (red line in Fig. 2c) remained constant. After $3 \mathrm{~h}$ the wall-losscorrected organic aerosol increased by roughly a factor of 3 from $\sim 7 \mu \mathrm{g} \mathrm{m}^{-3}$ of POA to $\sim 26 \mu \mathrm{g} \mathrm{m}^{-3}$ of organic aerosol (average of the $\omega=0$ and $\omega=1$ estimates in Fig. 2c). During the $3 \mathrm{~h}$ of UV irradiation much of the NO and primary hydrocarbons are oxidized to $\mathrm{NO}_{2}$ and oxygenated VOCs, respectively (Fig. 2a, b).

BC, POA and SOA for the entire fleet were measured in the chamber and are summarized in Fig. 3. The SOA data presented were measured in the chamber after $\sim 3 \mathrm{~h}$ 


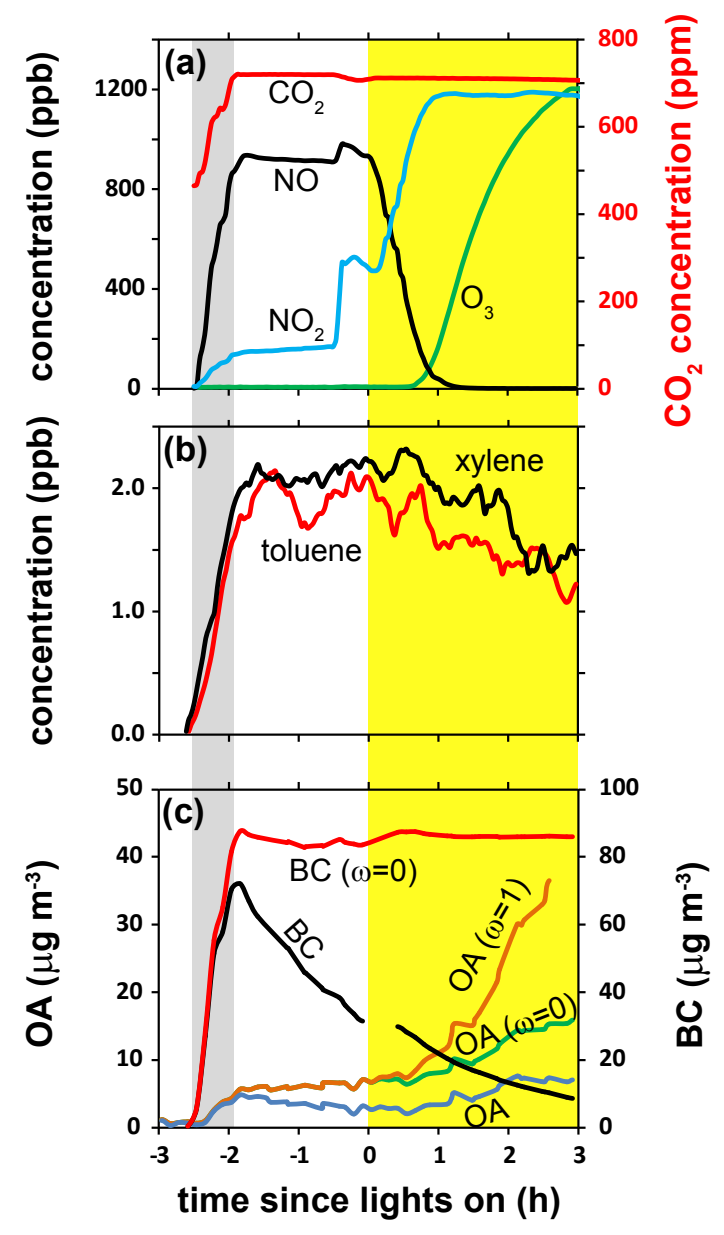

Fig. 2. Measured gas and particle evolution during a typical smog chamber experiment with a non-DPF-equipped vehicle (D3.13). Concentrations of (a) $\mathrm{NO}_{\mathrm{x}}, \mathrm{O}_{3}$ and $\mathrm{CO}_{2}$, (b) two single-ring aromatic SOA precursors, and (c) suspended and wall-loss-corrected organic PM and black carbon concentrations. The organic aerosol (OA) concentrations were corrected using two different methods $(\omega=0$ and $\omega=1)$ which provide an estimate of the uncertainty of the SOA production. The OA $(\omega=1)$ is capped at about $t=2.6 \mathrm{~h}$ when wall $\mathrm{OA} /$ suspended $\mathrm{OA}=5$. Between $-2.5 \mathrm{~h}<$ time $<-2.0 \mathrm{~h}$, the chamber was filled with dilute emissions from the vehicle; for $-2.0 \mathrm{~h}<$ time $<0 \mathrm{~h}$, the primary PM was characterized; for time $>0 \mathrm{~h}$, the UV lights were on and photooxidation generated SOA. The slight discontinuity at about $t=0 \mathrm{~h}$ for the uncorrected BC is an artifact of the Aethalometer ${ }^{\circledR}$ tape advance.

of photooxidation, which generated an $\mathrm{OH}$ exposure of 1$2 \times 10^{7}$ molecules $\mathrm{h} \mathrm{cm}^{-3}$. This corresponds to $3.5-7 \mathrm{~h}$ of equivalent atmospheric aging at typical summertime $\mathrm{OH}$ concentrations of $3 \times 10^{6}$ molecules $\mathrm{cm}^{-3}$. There was no evidence that SOA production was completed at the end of the experiment (after $3 \mathrm{~h}$ of oxidation). In some experiments the SOA production did slow as the $\mathrm{OH}$ levels decreased (due to consumption of the HONO by photolysis), but this did not appear to be related to availability of SOA precursors.
Measurements downwind of New England suggest SOA production continues for about $48 \mathrm{~h}$ at $\mathrm{OH}$ concentrations of $3 \times 10^{6}$ molecules $\mathrm{cm}^{-3}$ (de Gouw et al., 2005); if this applies to diesel exhaust, the data shown in Fig. 3 may substantially underestimate the SOA formation potential of diesel emissions.

The most striking feature in Fig. 3 is the very low BC and POA emissions and SOA formation for the catalyzed-DPFequipped vehicles (D1 and D2). For these experiments, the chamber measurements were all below the detection limit $\left(\sim 10 \mathrm{mg} \mathrm{kg}\right.$-fuel $\left.^{-1}\right)$.

There were substantial primary PM emissions and SOA formation in every experiment performed with a non-DPFequipped vehicle. Furthermore, the differences between the non-DPF-equipped vehicles - both the MDDVs and the HDDVs - were relatively modest compared to the differences between non-DPF- and DPF-equipped vehicles. For example, D3 ("D3 avg UDDS" in Fig. 3) emitted roughly onehalf and one-third as much POA as D5.3 and the DOCequipped MDDV ("2002 DOC") measured by Chirico et al. (2010), respectively (50 mg kg-fuel ${ }^{-1}$ vs. $80 \mathrm{mg} \mathrm{kg}$-fuel $^{-1}$ and $130 \mathrm{mg} \mathrm{kg}^{- \text {fuel }^{-1}}$ ), and BC levels were roughly comparable across these same experiments. Although qualitatively similar, BC and POA emissions and SOA formation for D4 differed somewhat more from the other non-DPF-equipped vehicles. However, this sort of vehicle-to-vehicle variability in vehicle emission rates is not surprising. May et al. (2014) compare the primary emissions data from these vehicles to the literature.

Many previous studies have reported $>90 \%$ reductions in primary PM from both heavy-duty (Herner et al., 2009; Millstein and Harley, 2010; Ratcliff et al., 2010) and lightduty (Ntziachristos et al., 2005; Matti Maricq, 2007) DPFequipped diesel engines. However, comparatively little has been published on the effect of aftertreatment on SOA formation. Figure 3 indicates that DOCs reduce SOA - more SOA was generated from MDDV and LDDV experiments without a DOC (D5.3 and 2000) than experiments with DOCs (D4.1 and 2002). We anticipate that the observed SOA reduction would mirror the reduction in NMOG emissions, since a subset of these emissions are SOA precursors. However, Fig. 4a indicates that the total NMOG emissions for D4.1

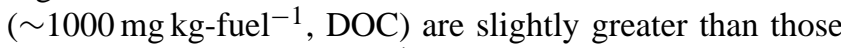
of D5.3 ( $\sim 700 \mathrm{mg} \mathrm{kg}-\mathrm{fuel}^{-1}$, no DOC). This suggests that either the DOC was malfunctioning in D4 or the higher SOA production of D5.3 could be due to differences in the composition of the emissions. Unfortunately, a measurement or reporting error from either the GC-MS or the flame ionization detector (FID) appears to have occurred during the D4.1 experiment because the sum of the masses of all the speciated compounds for D4.1 is greater than the total NMOG measured by FID. This technical difficulty may explain why the DOC-equipped vehicle's (D4's) NMOG was greater than the NMOG from the vehicle without a DOC (D5). 


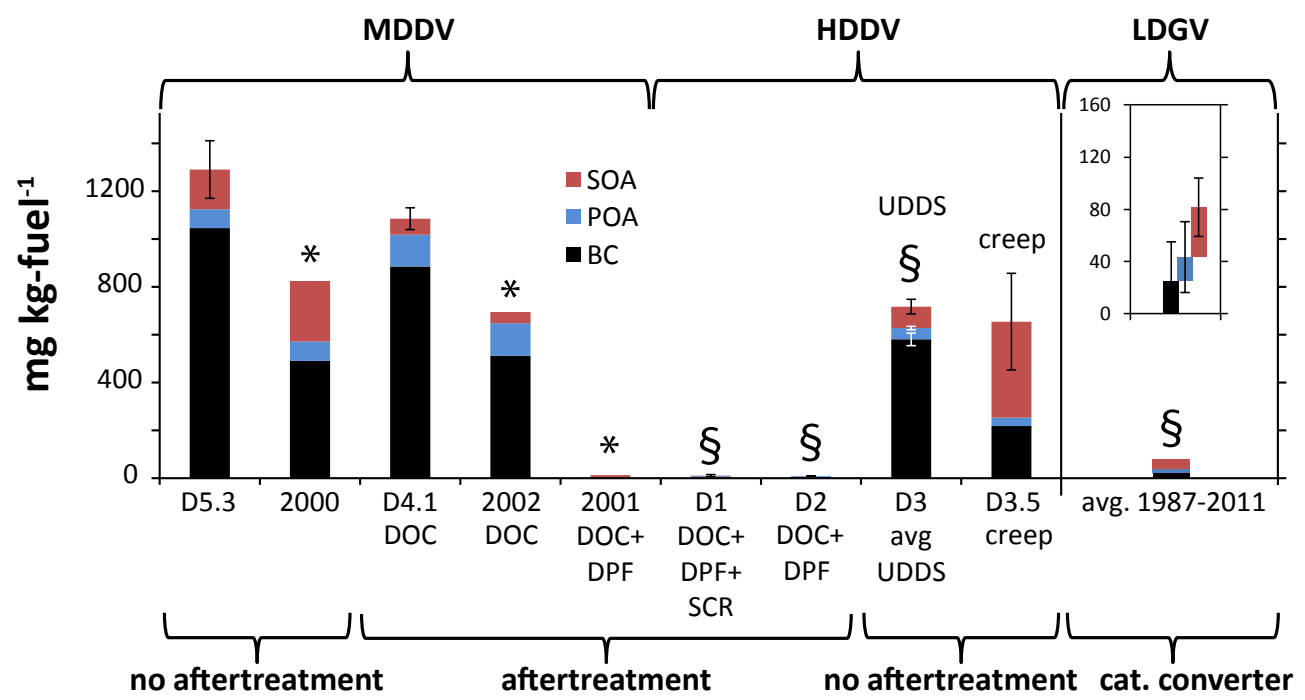

Fig. 3. Chamber measurements of black carbon, POA and SOA from medium- and heavy-duty diesel vehicles. Data for the three vehicles denoted by the $\S$ symbol are averages (error bars are $\pm 1 \sigma$ ) for multiple UDDS tests with each of those vehicles, including experiments utilizing different types of fuel. Data shown for D5.3, D4.1 and D3.5 represent a single experiment from each vehicle, and the error bars denote the SOA range obtained by applying the $\omega=0$ and $\omega=1$ wall-loss correction approaches. The three data sets denoted with an asterisk are from Chirico et al. (2010). The right-hand side of the figure shows average values from 15 light-duty gasoline vehicles (LDGV; MY1987 through MY2011) from Gordon et al. (2013a). The inset magnifies the LDGV data by a factor of 10.

The primary emissions and SOA formation from the DOCequipped MDDV (D4) were much higher than from the two catalyzed-DPF-equipped HDDVs (D1 and D2). In comparison, Chirico et al. (2010) and Samy and Zielinska (2010) report very low SOA formation from DOC-equipped engines. This suggests that the DOC on D4 might have been compromised; Chirico et al. (2010) also measured substantial SOA formation from a vehicle with a compromised DOC. The two DPF-equipped HDDVs are relatively new, well maintained and low mileage (Table 1). The DOC-equipped MDDV was recruited from the California in-use fleet; it was older with higher mileage than the two DPF-equipped HDDVs (Table 1). The results from Chirico et al. (2010) and this work underscore the potential effectiveness of catalyzed aftertreatment at reducing SOA formation from diesel vehicles, but also raise concerns about the durability of these systems.

For comparison, average BC and POA emissions and SOA production data from experiments with 15 different lightduty gasoline vehicles (MY1987 through MY2011) are included at the right side of Fig. 3 (Gordon et al., 2013a). As expected, $\mathrm{BC}$ emissions from any of the non-DPF-equipped diesels are much higher than for the gasoline vehicles. SOA formation from the DOC-equipped MDDV appears to be roughly comparable to that from the gasoline vehicles. SOA formation per mass of fuel burned from the non-DOCequipped diesel vehicles was greater than from the gasoline vehicles.

\subsection{Impact of driving cycle}

\subsubsection{Creep + idle vs. UDDS}

The low-engine-load creep + idle test cycle ("D3.5 creep" in Fig. 3) reduced BC emissions, but substantially increased SOA production relative to the "D3" tests using the UDDS cycle. The higher SOA formation was presumably linked to the factor-of-5 increase in NMOG emissions for the creep + idle experiment (Fig. 4). The reduction in BC at low load was consistent with many other studies (Presto et al., 2011; Lipsky and Robinson, 2006; Nakao et al., 2011) that have shown that the OC/EC ratio is inversely related to engine load.

No creep + idle smog chamber experiments were performed with DPF-equipped vehicles. However the NMOG emissions from these vehicles were much higher during creep + idle than UDDS tests ( 3.5 and $0.13 \mathrm{~g} \mathrm{~kg}$-fuel ${ }^{-1}$ for D2 and D1, respectively). In particular the D2 creep + idle NMOG emissions are more than half as large as those from the non-DPF-equipped D3 during creep + idle. Therefore, there may be significant SOA production under low-load driving conditions for DPF-equipped vehicles. The elevated NMOG emissions during the creep + idle test are likely due to lower exhaust temperatures, which reduce the efficacy of the catalyst.

\subsubsection{DPF Regeneration}

Figure 5 shows that POA emissions per mass of fuel consumed during active regeneration were comparable to those 

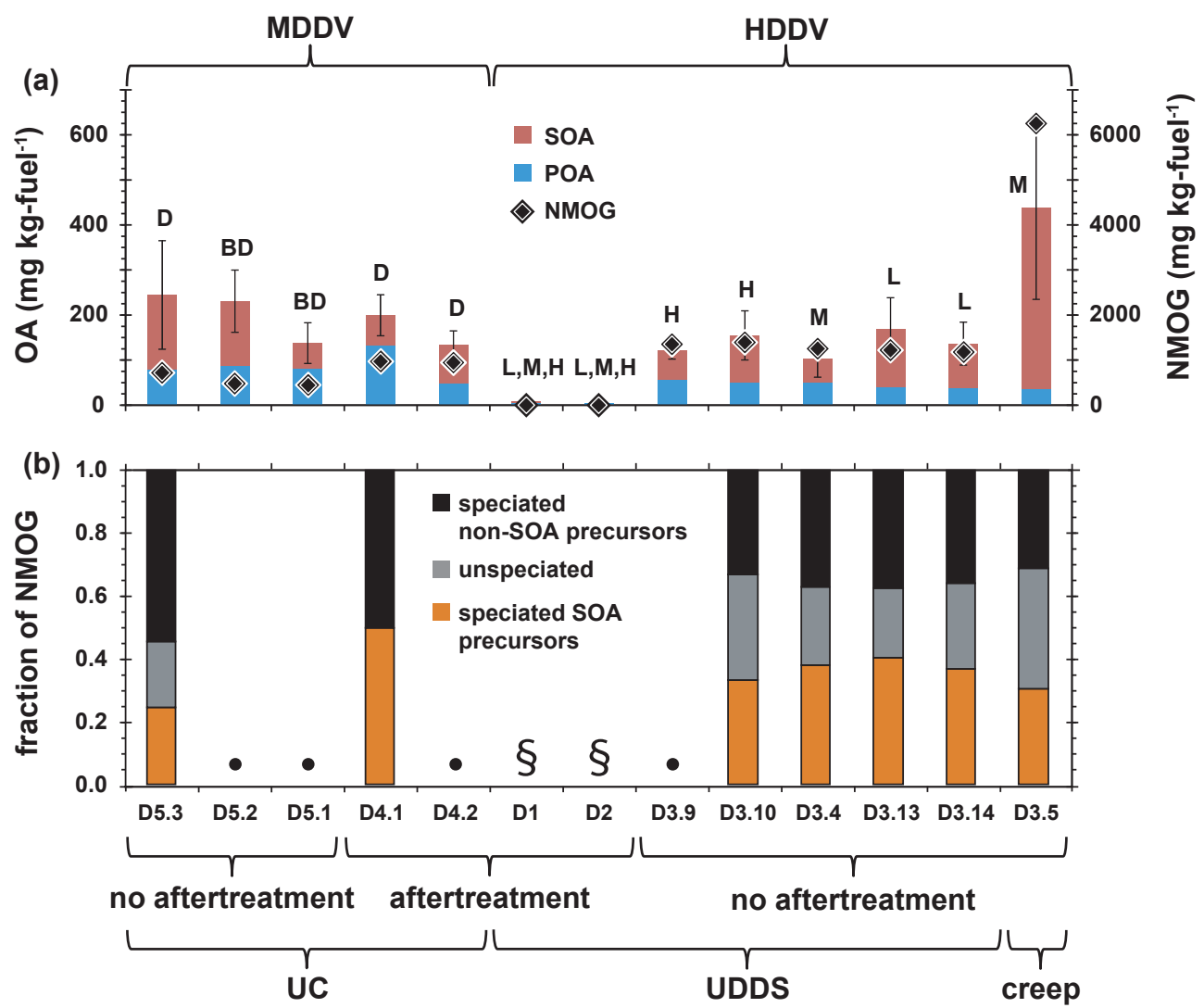

Fig. 4. (a) POA, SOA and total nonmethane organic gas (NMOG, plotted on right-hand axis) from medium- and heavy-duty diesel vehicles tested with different fuels $(\mathrm{D}=$ commercial ULSD, $\mathrm{BD}=100 \%$ soy biodiesel, $\mathrm{H}=$ high aromatic ULSD, $\mathrm{M}=$ mid-aromatic ULSD, $\mathrm{L}=\mathrm{low}$ aromatic ULSD), and driving cycles (UC for MDDV, UDDS and creep for HDDV). (b) Fractional contribution of speciated SOA precursors, speciated non-SOA precursors, and unspeciated organics to NMOG emissions (see Table S4 in the Supplement for a list of all species). Bars shown for the D3, D4 and D5 are from individual experiments. Error bars denote the range of wall-loss-corrected SOA estimates obtained by applying the $\omega=0$ and $\omega=1$ approaches. Data for the two DPF-equipped vehicles - D1 and D2 - are averages (error bars are $\pm 1 \sigma$ ) for multiple UDDS tests, including experiments utilizing different types of fuel. The bullet (•) symbol for D5.1 and D5.2 (both with BD fuel), D4.2, and D3.9 experiments indicates that no organic speciation data are available. The $\S$ symbol for the D1 and D2 experiments indicate that there is no organic composition data for these experiments because the NMOG emissions were below the detection limit.

measured during UDDS tests with the non-DPF-equipped HDDV (D3), but BC emissions during regeneration were much lower $\left(0.02\right.$ vs. $0.58 \mathrm{~g} \mathrm{~kg}_{\text {-fuel }}{ }^{-1}$ for the D1 and D3, respectively). A distinguishing feature of regeneration (compared to UDDS or creep) was the sulfate emissions ( 0.2 to $0.4 \mathrm{~g} \mathrm{~kg}^{- \text {fuel }^{-1}}$ ), which has also been reported by other studies (Vaaraslahti et al., 2004; Dwyer et al., 2010; Bergmann et al., 2009; Guo et al., 2003).

Figure 5 shows that there was substantial SOA formation from dilute active regeneration emissions. D2 emitted a sig-

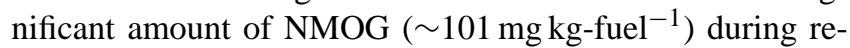
generation. Although D2's NMOG regeneration emissions were an order of magnitude lower than UDDS emissions from the non-DPF HDDVs (e.g., D3 average $=1260 \mathrm{mg} \mathrm{kg}$ fuel $^{-1}$ ), the amount of SOA produced during D2's regeneration was 2-3 times greater than what is produced by D3 during UDDS. A smaller amount $\left(8 \mathrm{mg} \mathrm{kg-fuel}{ }^{-1}\right)$ of NMOG was emitted by $\mathrm{D} 1$ during regeneration. Incomplete combus- tion of the fuel used to initiate active regeneration likely contributes to the SOA formation.

Given the significant primary PM emissions and SOA production from a single, active regeneration event (Fig. 5), it is important to estimate their impact on the overall contribution of DPF-equipped HDDV to ambient PM. This calculation depends on the frequency of active regeneration for the in-use fleet - a difficult metric to quantify (it depends on highly variable engine and environmental conditions as well as proprietary emission control algorithms, among other factors). Based on discussions with a senior industry scientist (T. V. Johnson, personal communication, 2013), we estimate active regeneration frequencies of once per 2000 miles $(3200 \mathrm{~km})$ for HDDVs manufactured during 2007-2009 and once per 10000 miles $(16000 \mathrm{~km})$ for HDDVs manufactured during 2010-2011. Combining our experimentally derived emission and SOA production factors for both active regeneration and for normal driving with these 


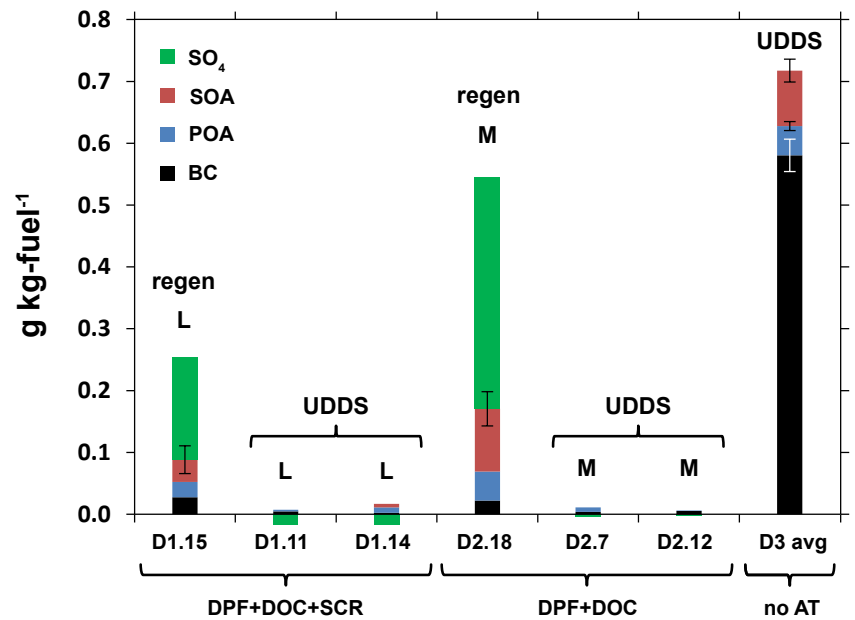

Fig. 5. Primary $P M$ emissions (BC, sulfate and POA) and SOA formed during active diesel particulate filter (DPF) regeneration ("regen"). As a benchmark, the median primary emissions and SOA production for control (UDDS, nonregeneration) experiments are also shown. For each vehicle the two control experiments and the regeneration used the same fuel $(\mathrm{L}=$ low aromatic and $\mathrm{M}=$ midaromatic). On the far right are the average values (error bars are $\pm 1 \sigma$ ) for all the UDDS tests with a non-DPF-equipped HDDV (D3). Error bars for the regeneration experiments denote the SOA range obtained by applying the $\omega=0$ and $\omega=1$ wall-loss correction approaches.

regeneration frequency estimates, we calculated the total $\mathrm{PM}$ (primary + SOA) contribution for the three classes of HDDVs. Taking the 2006 HDDV (D3) as the baseline, we estimated that the two DPF-equipped vehicles (D1 and D2) only contribute $0.1-1.5 \%$ as much $\mathrm{PM}$ mass $(\mathrm{BC}+\mathrm{POA}+$ $\left.\mathrm{SOA}+\mathrm{SO}_{4}\right)$ as the non-DPF-equipped vehicle. Therefore, active regeneration does not significantly degrade the overall performance of the DPF-equipped vehicle. Although Guo et al. (2003) did not consider SOA production, their estimate of DPF trapping efficiency (>97\% of PM by mass) is comparable to our estimate that DPFs reduce the total PM (primary + SOA) contribution by $98.5-99.9 \%$ relative to a non-DPFequipped vehicle.

In addition to periodic, discrete active regenerations, soot is also eliminated from the DPF through passive regeneration. No fuel is injected upstream of the DPF during passive regeneration; instead the soot oxidizes when hightemperature exhaust gases heat the DPF (typically during high-engine-load operations). While passive DPF regeneration is preferred over active regeneration (due to lower fuel consumption and reduced thermomechanical stress on the DPF substrate), many in-use diesel vehicles utilize active regeneration to some extent. For example, buses, refuse collection trucks, city delivery trucks and other non-longhaul diesel vehicles depend more heavily on active regeneration due to lower engine load and/or more frequent stopping/idling. The concomitant lower exhaust gas temperatures during these modes of operation necessitate more frequent active regeneration. Barring an aftertreatment breakthrough, diesel vehicles will continue to depend on active regeneration, although the frequency of active regenerations has decreased substantially for newer vehicles (T. V. Johnson, personal communication, 2013; Warner et al., 2010).

In our experiments, an active regeneration was performed as part of the pre-test and fuel switching protocols; thus, these vehicules underwent active regeneration more frequently than would occur under normal in-use conditions. Therefore, during these tests the DPFs likely contained less soot than they would under normal operating conditions, which could affect the passive regeneration and the emissions of both primary PM and SOA precursors. For example, more frequent active regenerations slightly reduce DPF trapping efficiency. During normal operation soot accumulates on the porous DPF substrate walls and provides an additional filtration layer, thereby increasing the $\sim 90 \%$ filtration efficiency of a freshly regenerated DPF to $\sim 99 \%$ for one containing some soot (Yang et al., 2009). It is not clear what impact this would have on SOA precursor emissions.

\subsubsection{Impacts of fuel chemistry and experimental repeatability}

Figure 4 presents the gas- and particle-phase data broken down by differences in fuel chemistry and expanded to show experimental repeatability. (Experiments with the two DPF-equipped HDDVs are not differentiated by fuel because emissions in every case were below the detection limit regardless of fuel type.) For example, instead of a single stacked bar for vehicle D5 (MDDV, no AT) as in Fig. 3, there are three stacked bars in Fig. 4a, corresponding to the three experiments with this vehicle, including two different fuels and a duplicate experiment. Figure $4 \mathrm{~b}$ shows the NMOG emissions separated into speciated SOA precursors, speciated non-SOA precursors and unspeciated (see Table S6 for a complete list of NMOG species, including SOA precursors). Speciated SOA precursors are aromatics and mid-weight $\left(\mathrm{C}_{9}\right.$ to $\mathrm{C}_{12}$ ) alkanes. Unspeciated emissions are defined as the difference between the total NMOG emissions and the sum of the speciated emissions. The unspeciated emissions are presumably a complex mixture of branched and cyclic isomers that were not separated by one-dimensional gas chromatography.

Although the aromatic content of the fuel and the emissions were positively correlated (see Fig. S4 in the Supplement), Fig. 4a, b indicate no systematic effect of fuel aromaticity on POA emissions or SOA production. EC emissions from the five experiments with D3 were also tightly grouped with no distinguishable trend based on fuel type (average $\pm 1 \sigma$ shown in Fig. 3; individual values not shown). Furthermore, the relative amounts of NMOG (Fig. 4b) in the different broad categories (speciated SOA precursor, speciated non-SOA precursor and unspeciated) are also 
identical for the D3 experiments (UDDS cycle) regardless of fuel type.

One of the MDDVs (D5) was tested with both commercial ULSD and B100 soy-based biodiesel. Although there was no effect on POA emissions, EC emissions were reduced by about a factor of 2 with B100 (data not shown), which is consistent with many studies (Lapuerta et al., 2008, and references therein) that report a $40-75 \%$ reduction in (primary) PM emissions when diesel is replaced with biodiesel. More data are required to determine conclusively biodiesel's impact on SOA formation. For the base experiment $\left(\mathrm{VOC} / \mathrm{NO}_{\mathrm{x}}\right.$ $\sim 3 \mathrm{ppbC} \mathrm{ppb}^{-1} \mathrm{NO}_{\mathrm{x}}$ ), there does not appear to be a significant effect. When the biodiesel experiment was repeated at a significantly lower $\mathrm{VOC} / \mathrm{NO}_{\mathrm{x}}$ ratio $\left(0.7 \mathrm{vs} .3 .8 \mathrm{ppbC} \mathrm{ppb}^{-1}\right.$ $\mathrm{NO}_{\mathrm{x}}$ ), the SOA production was reduced by more than a factor of 2 (experiments D5.2 and D5.1, respectively). This may be caused by high- $\mathrm{NO}_{\mathrm{x}}$ conditions causing $\mathrm{NO}$ and $\mathrm{NO}_{2}$ to react with organoperoxy radicals $\left(\mathrm{RO}_{2}\right)$, which changes the distribution (and volatilities) of oxidation products, reducing SOA yields. Other researchers have shown that SOA production is reduced in single-component smog chamber studies when $\mathrm{VOC} / \mathrm{NO}_{\mathrm{x}}$ is reduced (Presto et al., 2005a; Song et al., 2005).

Figure 4 demonstrates good repeatability of these experiments, especially with the HDDVs. The duplicate MDDV experiments labeled "D" produced comparable amounts of SOA and NMOG, but their POA emissions differed. POA emissions from the two MDDV experiments labeled "BD" were nearly identical. The moderate difference in SOA production for these two experiments is likely due to the fact that they were not true duplicates: the experiment with the lower SOA was stopped after only $1.5 \mathrm{~h}$ of photooxidation rather than $3 \mathrm{~h}$ for the other BD experiment.

\subsubsection{SOA mass closure}

To investigate the relationship between NMOG emissions and SOA production, we calculated an effective SOA yield, defined as the ratio of the measured SOA mass after $3 \mathrm{~h}$ of photooxidation to the estimated mass of reacted SOA precursors. This is a standard measure of SOA production in smog chamber studies. It is the conversion efficiency from precursor to SOA mass. In this work, we use the term "effective" yield because diesel exhaust is comprised of a complex mix of species of which only a subset was quantified by the GC analysis. Therefore, we can only estimate the mass of reacted organic precursors. The reacted precursor mass was calculated from the initial concentration of each species (inferred from the measurements in the CVS), the $\mathrm{OH}$ exposure in the chamber and the reaction rate for the species with $\mathrm{OH}$. The speciated SOA precursors included in this analysis were single-ring aromatics $\left(\mathrm{C}_{6}\right.$ to $\left.\mathrm{C}_{12}\right)$ and mid-weight VOCs $\left(\mathrm{C}_{9}\right.$ to $\mathrm{C}_{12}$ ) (see Table $\mathrm{S} 4$ in the Supplement). These are the compounds that are traditionally included in SOA models (Heald et al., 2005; Hennigan et al., 2011; Miracolo et al., 2010,
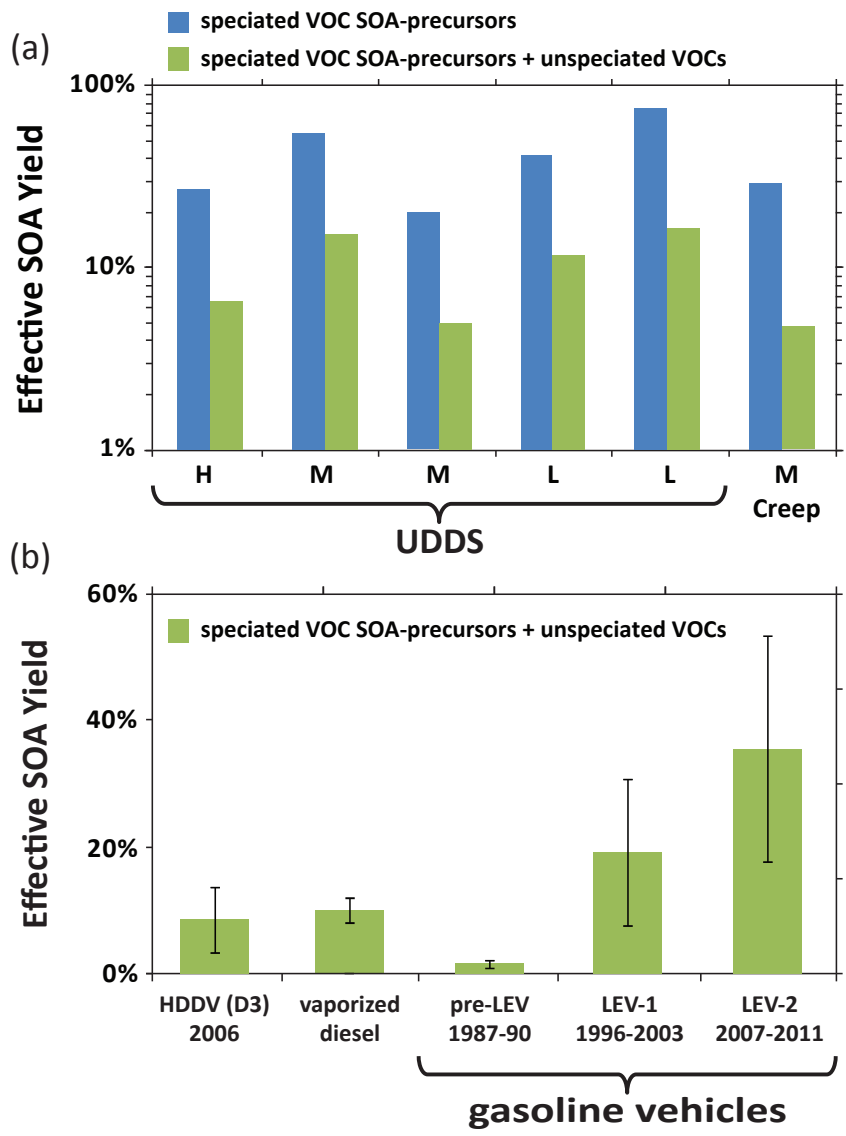

Fig. 6. (a) Estimated effective SOA yields for HDDVs without DPF (D3) fueled with high (H)-, medium (M)- and low (L)-aromatic ultralow sulfur diesel. Yields in (a) are based on the UDDS driving cycle except for the creep + idle driving cycle ("M Creep"). (b) compares the median effective yields (using the lower of the two yield estimates from a) for the 5 diesel UDDS experiments to vaporized diesel (Jathar et al., 2013a) and to gasoline vehicles from 15 unique vehicles in 3 different emissions categories (pre-LEV, LEV1, LEV-2) (Gordon et al., 2013a). Diesel experiments were "hot start" (engine was warmed prior to test cycle), but gasoline experiments shown in (b) were all "cold start". The DPF-equipped HDDVs (D1 and D2) are not shown because SOA production from the emissions of these vehicles was below the detection limit (Fig. 4). The error bars represent the standard deviations of the medians.

2011; Vutukuru et al., 2006). For the HDDV experiments unspeciated NMOG with Kovats indices $\geq 800$ (i.e., higher molecular weight than n-octane) were also assumed to be SOA precursors; NMOG with Kovats indices $<800$ were assumed to be nonprecursors (see Table S4 in the Supplement).

Figure 6a presents the effective SOA yield estimates for the non-DPF-equipped HDDV experiments with low-, medium- and high-aromaticity diesel fuel. If only traditional SOA precursors are included in the analysis $\left(\mathrm{C}_{6}\right.$ to $\mathrm{C}_{12}$ single-ring aromatics and mid-weight alkanes and other species with Kovats $\geq 800$ ), then the estimated yields are $20-75 \%$ (the wide range is likely due in part to 
experiment-to-experiment differences in chamber PM levels which alter gas-particle partitioning). This is higher than yields from most single-compound smog chamber studies, which are generally 5 to $20 \%$ across a wide range of experimental conditions (Chan et al., 2009; Hildebrandt et al., 2009; Ng et al., 2007; Presto et al., 2010; Tkacik et al., 2012). Odum et al. (1997) reported yields from whole gasoline vapors - a more complex system (and therefore presumably closer to combustion emissions) than single compounds that range from about 2 to $5 \%$ at $\left(\mathrm{C}_{\mathrm{OA}} \approx 10 \mu \mathrm{g} \mathrm{m}^{-3}\right)$ (Odum et al., 1997). Compared to those studies, the yields required to explain the measured SOA production with only speciated SOA precursors seem unrealistically high, indicating that additional precursors are required for mass closure. Previous studies have also demonstrated that traditional SOA precursors do not explain the amount of SOA formed from the photooxidation of combustion products of various fuels, including wood, diesel and jet fuel (Weitkamp et al., 2007; Grieshop et al., 2009; Miracolo et al., 2011). Chemical transport models that only account for traditional, speciated SOA precursors also systematically underpredict the ambient SOA levels (Heald et al., 2005; Volkamer et al., 2006; de Gouw et al., 2005).

A challenge to performing SOA closure studies is that not all of the NMOG can be speciated using the traditional onedimensional gas chromatography employed here (Schauer et al., 1999). Figure 4b indicates that in all but one experiment a significant fraction (on average $30 \%$ ) of the NMOG emissions that could not be speciated. This is similar to measurements by Schauer et al. (1999). The unspeciated emissions are presumably high-molecular-weight alkanes, and the majority of these are expected to be intermediate-volatility organic compounds (IVOCs) (Robinson et al., 2007). To include them in the effective yield analysis, we assume that the unspeciated mass reacts at $2 \times 10^{-11} \mathrm{~cm}^{3}$ molecules ${ }^{-1} \mathrm{~s}^{-1}$, which is representative of published kinetic data for large saturated alkanes (Atkinson and Arey, 2003).

Figure 6a indicates that effective yields range from 4 to $19 \%$ when both the unspeciated NMOG and the speciated SOA precursors are included in the analysis. This range is plausible given data from single-component chamber experiments (Hildebrandt et al., 2009; Odum et al., 1996; Presto et al., 2010). This analysis indicates that more than half of the SOA formed in dilute diesel exhaust likely comes from unspeciated emissions that are frequently not correctly accounted for in chemical transport models. This issue is discussed in more detail in an upcoming manuscript (Jathar et al., 2013b).

Figure $6 \mathrm{~b}$ compares the effective yields calculated for the HDDVs without a DPF (D3, UDDS only) to similar estimates for 14 different gasoline vehicles (Gordon et al., 2013a) and to vaporized diesel fuel (Jathar et al., 2013a). The median effective yield for dilute diesel exhaust $(\sim 10 \%$ if S/IVOCs and unspeciated compounds are included) is roughly equal to vaporized diesel fuel. It also falls between the medians for pre-LEV and LEV-1 gasoline vehicles.

The effective yield estimates plotted in Fig. $6 \mathrm{~b}$ are only a relative measure of SOA production. The ultimate contribution of a vehicle's emissions depends on both the yield and precursor emission rate. Figure 3 shows that the net effect of both of these factors is that the absolute amount of SOA production for the D3 HDDV operated over the UDDS cycle is roughly $60 \%$ larger than the median gasoline vehicle tested by Gordon et al. (2013a).

It is important to note that all of the HDDV experiments discussed here were "hot start" (engine was warmed prior to test cycle), whereas the gasoline experiments shown in Fig. 6b were all "cold start." For gasoline vehicles, hotstart emission produce significantly less SOA than cold-start emissions (Gordon et al., 2013a). Thus, it is possible that this experimental difference negatively biases the HDDV SOA data relative to the gasoline data. However, it is unclear whether differences in engine/catalyst temperature have the same effect (in magnitude or direction) on the effective SOA yield for gasoline and diesel vehicles. Furthermore, all of the MDDV experiments were cold start. Figure 3 indicates that there was not a significant difference in the mass of SOA produced during the cold-start MDDV and the hot-start UDDS with D3. However, additional research is needed to better understand SOA production from cold-start versus hot-start diesel vehicle emissions.

\section{Conclusions}

Smog chamber experiments were conducted to investigate SOA formation from dilute emissions from two mediumduty and three heavy-duty diesel vehicles. While the number of vehicles tested in this study was limited, the vehicles were specifically chosen to investigate the range of current exhaust aftertreatment technologies. The primary PM results are consistent with many previous studies (May et al., 2014). In particular, the conclusion that the two DPF-equipped vehicles emitted essentially no primary PM (BC or organics) during high-speed and transient operations is congruent with numerous independent reports (Chirico et al., 2010; Guo et al., 2003; Herner et al., 2011; Liu et al., 2008). This study extended that previous work to demonstrate that SOA production from these emissions was also very low (below the detection limit). Therefore, catalyzed DPFs appear to effectively control both primary and secondary PM from diesel vehicles.

While these experiments did not test the same vehicle with and without a DPF, there is strong evidence that our conclusions are not limited by this apparent source of uncertainty. There is a truly dramatic difference between the emissions (PM, NMOG, etc.) from those vehicles with a DPF and those without a DPF. For example, the NMOG emissions from the catalyzed-DPF-equipped diesels were 2 orders of magnitude 
lower than vehicles without aftertreatment. It is highly unlikely that these reductions could be achieved without aftertreatment, for, if this were possible, engine manufacturers would not be adding DPFs to meet current regulations. In other words, DPF- and non-DPF-equipped vehicles operate in totally distinct emissions regimes. This hypothesis is supported by comparisons of our primary emissions data with the broader literature (May et al., 2014).

The impact of DPF regeneration on PM production is not well understood, and depends on actual in-use conditions. In this study, primary PM emissions as well as SOA and sulfate production from DPF-equipped vehicles were observed during active regeneration. Further investigation is needed to refine estimates of the PM contribution from passive and active regeneration, but our results support the conclusion that active DPF regeneration contributes relatively little PM over a vehicle's operation cycle (normal driving + regeneration), even when SOA production is included.

Substantial SOA was formed when emissions from MDDVs and HDDVs not equipped with DPFs were photooxidized in the smog chamber for $3 \mathrm{~h}$ - with the emissions from some vehicles generating twice as much SOA as POA. Although SOA production from diesel- and biodiesel-fueled vehicles without a DPF was significant on an absolute basis, after $3 \mathrm{~h}$ of photooxidation the net PM (primary + secondary) levels in the chamber were still dominated by the primary emissions because of the high levels of BC. However, BC's dominant role in PM emissions/production from diesel vehicles could be due in part to the limited $\mathrm{OH}$ exposure and/or conservative approach we have taken in estimating SOA production. As previously discussed, our SOA estimates do not include the loss of organic vapors to the chamber walls. Kokkola et al. (2014) suggest that ambient SOA mass production may be underpredicted in chamber experiments by a factor of 4 due to the loss of low-volatility vapors to the walls (Kokkola et al., 2014). Furthermore, Matsunaga and Ziemann (2010) show that for a range of gas-phase compounds relevant to our study the $\mathrm{OC}$ in the chamber will reside overwhelmingly in the chamber walls (Matsunaga and Ziemann, 2010). Absorption of SOA precursors by the chamber walls would imply that the effective SOA yields in Fig. 6 are lower limits on the yields expected in the ambient atmosphere and that SOA may constitute a larger fraction of total PM.

While net PM and POA were comparable for slow/idle operations (i.e., the creep + idle driving cycle) and highspeed urban operation (i.e., the UDDS cycle), SOA production from slow/idle operation was 3-4 times larger than SOA production from the UDDS cycle. This appears to be due to the much higher NMOG emissions during the slow/idle operation. Reduced $\mathrm{BC}$ emissions partially offset the increased SOA production during the slow/idle tests. For one of the MDDVs, switching from ULSD to B100 biodiesel reduced BC substantially, but POA emissions and SOA production were unchanged.
For the HDDVs without a DPF, an effective SOA yield was calculated using measurements of the speciated and unspeciated nonmethane organic gases. The SOA could not be explained by speciated VOCs (i.e., traditional SOA precursors) alone. We hypothesize that unspeciated organics $(\sim 30 \%$ of the NMOG emissions) are important, additional SOA precursors. If these emissions are included in the analysis (in addition to speciated, known SOA precursors), then the estimated effective SOA yield ranged from 4 to $19 \%$, comparable to the yield of single-ring aromatics and larger alkanes (Donahue et al., 2005; Hildebrandt et al., 2009; Odum et al., 1996; Presto et al., 2010). The variability in yield estimates is due, in part, to experiment-to-experiment differences in chamber $\mathrm{OH}$ and PM levels.

The aromatic content of the three different test fuels used in HDDV tests had no effect on the amount of primary PM emissions or SOA production. In contrast, Odum et al. (1997) found that fuel aromaticity accurately predicted SOA yields when vaporized gasoline was photooxidized (Odum et al., 1997). The difference between our results and those of Odum et al. (1997) underscores the strong distinction between photooxidation of actual vehicle emissions versus photooxidation of vaporized fuel. Our results suggest that reformulating diesel fuel by altering aromatic content alone is not likely to have a significant impact on either primary or secondary PM. Driving cycle, on the other hand, had a large impact on SOA production. The large amounts of SOA formed from slow/idle emissions means that efforts to limit truck idling may be a more effective approach than fuel reformulation to limit the contribution of diesel emissions to ambient PM.

Throughout this paper reported SOA production was based on AMS measurements. If SMPS-derived estimates were used instead, the clear distinction between vehicles with and without aftertreatment becomes even more pronounced. This is due to the fact that the SMPS-derived estimates of SOA are approximately a factor of 3 higher than AMS-derived SOA estimates for the non-DPF-equipped vehicles but remain zero for the DPF equipped vehicles whether calculated from AMS or SMPS data. In addition, SOA yields would increase by a similar amount to a median of $\sim 27 \%$, and the ratio of $\mathrm{SOA}_{\text {creep }}+$ idle $/ \mathrm{SOA}$ UDDS would be $\sim 10$ rather than 3-4. Using SMPS data rather than AMS data does not change the conclusion that fuel chemistry has little or no effect on primary PM emissions or SOA formation.

\section{Supplementary material related to this article is available online at http://www.atmos-chem-phys.net/14/ 4643/2014/acp-14-4643-2014-supplement.pdf.}

Acknowledgements. This research would not have been possible without the hard work of the excellent and dedicated staff at the California Air Resources Board Heavy-duty Vehicle and Haagen-Smit laboratories. Funding was provided by the US Environmental Protection Agency National Center for Environmental 
Research (NCER) through the STAR program (R834554) and the Coordinating Research Council through project no. A-74/E-96. The California Air Resources Board provided significant in-kind support for the testing. The views, opinions, and/or findings contained in this paper are those of the authors and should not be construed as an official position of the funding agencies.

Edited by: A. Virtanen

\section{References}

Allan, J. D., Delia, A. E., Coe, H., Bower, K. N., Alfarra, M. R., Jimenez, J. L., Middlebrook, A. M., Drewnick, F., Onasch, T. B., and Canagaratna, M. R.: A generalised method for the extraction of chemically resolved mass spectra from Aerodyne aerosol mass spectrometer data, J. Aerosol Sci., 35, 909-922, 2004.

Anderson, R. C. and Rykowski, R. A.: Reformulated gasoline, in: Economic Analyses at EPA: Assessing Regulatory Impact, edited by: Morgenstern, R. D., 391-418, 1997.

Atkinson, R. and Arey, J.: Atmospheric degradation of volatile organic compounds, Chemical Reviews, 103, 4605-4638, 2003.

Bahreini, R., Middlebrook, A., de Gouw, J., Warneke, C., Trainer, M., Brock, C., Stark, H., Brown, S., Dube, W., and Gilman, J.: Gasoline emissions dominate over diesel in formation of secondary organic aerosol mass, Geophys. Res. Lett., 39, L06805, doi:10.1029/2011GL050718, 2012.

Bergmann, M., Kirchner, U., Vogt, R., and Benter, T.: On-road and laboratory investigation of low-level PM emissions of a modern diesel particulate filter equipped diesel passenger car, Atmos. Environ., 43, 1908-1916, doi:10.1016/j.atmosenv.2008.12.039, 2009.

California Air Resources Board: Driving Cycles - Models of Driving Behavior, California Air Resources Board's Emissions Inventory Series, 1, 1996.

California Air Resources Board: S.O.P. MLD 119: Procedure for the Direct Determination of Total Non-Methane Hydrocarbons and Methane in Motor Vehicle Exhaust Using Cryogenic Preconcentration and Flame Ionization Detection, http://www.arb.ca.gov/ testmeth/slb/sop119.pdf (last access: 15 April 2014), 2001.

California Air Resources Board: S.O.P. MLD 102/103: Procedure For The Determination Of C2 To C12 Hydrocarbons In Automotive Exhaust Samples By Gas Chromatography, http://www.arb. ca.gov/testmeth/slb/sop102-103v2-2.pdf (last access: 15 April 2014), 2004.

California Air Resources Board: S.O.P. MLD 104: Determination of Aldehyde and Ketone Compounds in Automotive Source Samples by High Performance Liquid Chromatography, www.arb. ca.gov/testmeth/slb/sop104v3.pdf (last access: 15 April 2014), 2006.

Carter, W. P., Luo, D., Malkina, I. L., and Pierce, J. A.: Environmental chamber studies of atmospheric reactivities of volatile organic compounds: Effects of varying chamber and light source, Statewide Air Pollution Research Center, p. 1, 1995.

CFR: Code of Federal Regulations, Protection of the Environment, Title 40, Part 1065 Engine Testing Procedures, US Government Printing Office, Washington, DC, 2008.

Chan, A. W. H., Kautzman, K. E., Chhabra, P. S., Surratt, J. D., Chan, M. N., Crounse, J. D., Kürten, A., Wennberg, P. O., Flagan, R. C., and Seinfeld, J. H.: Secondary organic aerosol formation from photooxidation of naphthalene and alkylnaphthalenes: implications for oxidation of intermediate volatility organic compounds (IVOCs), Atmos. Chem. Phys., 9, 3049-3060, doi:10.5194/acp-9-3049-2009, 2009.

Chirico, R., DeCarlo, P. F., Heringa, M. F., Tritscher, T., Richter, R., Prévôt, A. S. H., Dommen, J., Weingartner, E., Wehrle, G., Gysel, M., Laborde, M., and Baltensperger, U.: Impact of aftertreatment devices on primary emissions and secondary organic aerosol formation potential from in-use diesel vehicles: results from smog chamber experiments, Atmos. Chem. Phys., 10, 11545-11563, doi:10.5194/acp-10-11545-2010, 2010.

Chow, J., Watson, J., Pritchett, L., Pierson, W., Frazier, C., and Purcell, R.: The DRI thermal optical reflectance carbon analysis system - description, evaluation and applications in United-States air quality studies, Atmos. Environ. A Gen. Top, 27, 1185-1201, 1993.

de Gouw, J. A., Middlebrook, A. M., Warneke, C., Goldan, P. D., Kuster, W. C., Roberts, J. M., Fehsenfeld, F. C., Worsnop, D. R., Canagaratna, M. R., Pszenny, A. A. P., Keene, W. C., Marchewka, M., Bertman, S. B., and Bates, T. S.: Budget of organic carbon in a polluted atmosphere: Results from the New England Air Quality Study in 2002, J. Geophys. Res., 110, D16305, doi:10.1029/2004jd005623, 2005.

Donahue, N. M., Huff Hartz, K. E., Chuong, B., Presto, A. A., Stanier, C. O., Rosenhorn, T., Robinson, A. L., and Pandis, S. N.: Critical factors determining the variation in SOA yields from terpene ozonolysis: A combined experimental and computational study, Faraday Discuss., 130, 295-309, 2005.

Dwyer, H., Ayala, A., Zhang, S., Collins, J., Huai, T., Herner, J., and Chau, W.: Emissions from a diesel car during regeneration of an active diesel particulate filter, J. Aerosol Sci., 41, 541-552, doi:10.1016/j.jaerosci.2010.04.001, 2010.

Farmer, D., Matsunaga, A., Docherty, K., Surratt, J., Seinfeld, J., Ziemann, P., and Jimenez, J.: Response of an aerosol mass spectrometer to organonitrates and organosulfates and implications for atmospheric chemistry, Proc. Natl. Acad. Sci., 107, 66706675, doi:10.1073/pnas.0912340107 2010.

Fujita, E. M., Campbell, D. E., Stockwell, W., Keislar, R., Zielinska, B., Sagebiel, J. C., Goliff, W., Keith, M., and Bowen, J. L.: Weekend/weekday ozone observations in the South Coast Air Basin Volume II: Analysis of air quality data, Final report prepared for the National Renewable Energy Laboratory, Golden, CO, and the Coordinating Research Council by the Desert Research Institute, Reno, NV, April, 2002.

Gentner, D. R., Isaacman, G., Worton, D. R., Chan, A. W. H., Dallmann, T. R., Davis, L., Liu, S., Day, D. A., Russell, L. M., Wilson, K. R., Weber, R., Guha, A., Harley, R. A., and Goldstein, A. H.: Elucidating secondary organic aerosol from diesel and gasoline vehicles through detailed characterization of organic carbon emissions, Proc. Natl. Acad. Sci., 109, 18318-18323, doi:10.1073/pnas.1212272109, 2012.

Gordon, T. D., Presto, A. A., May, A. A., Nguyen, N. T., Lipsky, E. M., Donahue, N. M., Gutierrez, A., Zhang, M., Maddox, C., Rieger, P., Chattopadhyay, S., Maldonado, H., Maricq, M. M., and Robinson, A. L.: Secondary Organic Aerosol Formation Exceeds Primary Particulate Matter Emissions for Light-Duty Gasoline Vehicles, Atmos. Chem. Phys. Discuss., 13, 2317323216, doi:10.5194/acpd-13-23173-2013, 2013a. 
Gordon, T. D., Tkacik, D. S., Presto, A. A., Zhang, M., Jathar, S. H., Nguyen, N. T., Massetti, J., Truong, T., Cicero-Fernandez, P., Maddox, C., Rieger, P., Chattopadhyay, S., Maldonado, H., Maricq, M. M., and Robinson, A. L.: Primary Gas- and ParticlePhase Emissions and Secondary Organic Aerosol Production from Gasoline and Diesel Off-Road Engines, Environ. Sci. Technol., 47, 14137-14146, doi:10.1021/es403556e, 2013 b.

Grieshop, A. P., Logue, J. M., Donahue, N. M., and Robinson, A. L.: Laboratory investigation of photochemical oxidation of organic aerosol from wood fires 1: measurement and simulation of organic aerosol evolution, Atmos. Chem. Phys., 9, 1263-1277, doi:10.5194/acp-9-1263-2009, 2009.

Guo, G., Xu, N., Laing, P. M., Hammerle, R. H., and Maricq, M. M.: Performance of a catalyzed-diesel particulate filter system during soot accumulation and regeneration, SAE Transactions, 112, 94-101, 2003.

Hallquist, M., Wenger, J., Baltensperger, U., Rudich, Y., Simpson, D., Claeys, M., Dommen, J., Donahue, N., George, C., and Goldstein, A.: The formation, properties and impact of secondary organic aerosol: current and emerging issues, Atmos. Chem. Phys., 9, 5155-5235, doi:10.5194/acp-9-5155-2009, 2009.

Heald, C. L., Jacob, D. J., Park, R. J., Russell, L. M., Huebert, B. J., Seinfeld, J. H., Liao, H., and Weber, R. J.: A large organic aerosol source in the free troposphere missing from current models, Geophys. Res. Lett, 32, 1-4, 2005.

Hennigan, C., Miracolo, M., Engelhart, G., May, A., Presto, A., Lee, T., Sullivan, A., McMeeking, G., Coe, H., and Wold, C.: Chemical and physical transformations of organic aerosol from the photo-oxidation of open biomass burning emissions in an environmental chamber, Atmos. Chem. Phys., 11, 7669-7686, doi:10.5194/acp-11-7669-2011, 2011.

Herner, J. D., Hu, S., Robertson, W. H., Huai, T., Collins, J. F., Dwyer, H., and Ayala, A.: Effect of Advanced Aftertreatment for $\mathrm{PM}$ and $\mathrm{NO}_{\mathrm{x}}$ Control on Heavy-Duty Diesel Truck Emissions, Environ. Sci. Technol., 43, 5928-5933, doi:10.1021/es9008294, 2009.

Herner, J. D., Hu, S., Robertson, W. H., Huai, T., Chang, M. C. O., Rieger, P., and Ayala, A.: Effect of Advanced Aftertreatment for $\mathrm{PM}$ and $\mathrm{NO}_{\mathrm{x}}$ Reduction on Heavy-Duty Diesel Engine Ultrafine Particle Emissions, Environ. Sci. Technol., 45, 2413-2419, doi:10.1021/es102792y, 2011.

Hildebrandt, L., Donahue, N., and Pandis, S.: High formation of secondary organic aerosol from the photo-oxidation of toluene, Atmos. Chem. Phys., 9, 2973-2986, doi:10.5194/acp-9-29732009, 2009.

Jathar, S. H., Miracolo, M. A., Tkacik, D. S., Donahue, N. M., Adams, P. J., and Robinson, A. L.: Secondary organic aerosol from photo-oxidation of evaporated fuel: Experimental results and implications for aerosol formation from combustion emissions, Environ. Sci. Technol., 88, 247-260, doi:10.1016/j.atmosenv.2014.01.046, 2013a.

Jathar, S. H., Gordon, T. D., Hennigan, C. J., Pye, H. O. T., Adams, P. J., Donahue, N. M., and Robinson, A. L.: Unspeciated organic emissions from combustion sources and their influence on the secondary organic aerosol budget in the United States, submitted to Proc. Natl. Acad. Sci., 2013b.

Jimenez, J. L., Canagaratna, M. R., Donahue, N. M., Prevot, A. S. H., Zhang, Q., Kroll, J. H., DeCarlo, P. F., Allan, J. D., Coe, H., Ng, N. L., Aiken, A. C., Docherty, K. S., Ulbrich, I. M.,
Grieshop, A. P., Robinson, A. L., Duplissy, J., Smith, J. D., Wilson, K. R., Lanz, V. A., Hueglin, C., Sun, Y. L., Tian, J., Laaksonen, A., Raatikainen, T., Rautiainen, J., Vaattovaara, P., Ehn, M., Kulmala, M., Tomlinson, J. M., Collins, D. R., Cubison, M. J., Dunlea, J., Huffman, J. A., Onasch, T. B., Alfarra, M. R., Williams, P. I., Bower, K., Kondo, Y., Schneider, J., Drewnick, F., Borrmann, S., Weimer, S., Demerjian, K., Salcedo, D., Cottrell, L., Griffin, R., Takami, A., Miyoshi, T., Hatakeyama, S., Shimono, A., Sun, J. Y., Zhang, Y. M., Dzepina, K., Kimmel, J. R., Sueper, D., Jayne, J. T., Herndon, S. C., Trimborn, A. M., Williams, L. R., Wood, E. C., Middlebrook, A. M., Kolb, C. E., Baltensperger, U., and Worsnop, D. R.: Evolution of Organic Aerosols in the Atmosphere, Science, 326, 1525-1529, doi:10.1126/science.1180353, 2009.

Kanakidou, M., Seinfeld, J., Pandis, S., Barnes, I., Dentener, F., Facchini, M., Van Dingenen, R., Ervens, B., Nenes, A., and Nielsen, C.: Organic aerosol and global climate modelling: a review, Atmos. Chem. Phys., 5, 1053-1123, doi:10.5194/acp-5-1053-2005, 2005.

Khalek, I. A., Bougher, T. L., Merritt, P. M., and Zielinska, B.: Regulated and Unregulated Emissions from Highway Heavy-Duty Diesel Engines Complying with U.S. Environmental Protection Agency 2007 Emissions Standards, J. Air Waste Manage. Assoc., 61, 427-442, doi:10.3155/1047-3289.61.4.427, 2011.

Kirchstetter, T. W. and Novakov, T.: Controlled generation of black carbon particles from a diffusion flame and applications in evaluating black carbon measurement methods, Atmos. Environ., 41, 1874-1888, 2007.

Kokkola, H., Yli-Pirilä, P., Vesterinen, M., Korhonen, H., Keskinen, H., Romakkaniemi, S., Hao, L., Kortelainen, A., Joutsensaari, J., Worsnop, D. R., Virtanen, A., and Lehtinen, K. E. J.: The role of low volatile organics on secondary organic aerosol formation, Atmos. Chem. Phys., 14, 1689-1700, doi:10.5194/acp-14-16892014, 2014.

Kroll, J. H. and Seinfeld, J. H.: Chemistry of secondary organic aerosol: Formation and evolution of low-volatility organics in the atmosphere, Atmos. Environ., 42, 3593-3624, doi:10.1016/j.atmosenv.2008.01.003, 2008.

Lammert, M., McCormick,R., Sindler,P., Williams,A.: Effect of B20 and Low Aromatic Diesel on Transit Bus $\mathrm{NO}_{\mathrm{x}}$ Emissions Over Driving Cycles with a Range of Kinetic Intensity, SAE Int. J. Fuels Lubr., 5, 1345-1359, doi:10.4271/2012-01-1984., 2012.

Lapuerta, M., Armas, O., and Rodríguez-Fernández, J.: Effect of biodiesel fuels on diesel engine emissions, Prog. Energy Comb. Sci., 34, 198-223, doi:10.1016/j.pecs.2007.07.001, 2008.

Lim, Y. B. and Ziemann, P. J.: Chemistry of Secondary Organic Aerosol Formation from $\mathrm{OH}$ Radical-Initiated Reactions of Linear, Branched, and Cyclic Alkanes in the Presence of $\mathrm{NO}_{\mathrm{x}}$, Aerosol Sci. Technol., 43, 604-619, doi:10.1080/02786820902802567, 2009.

Lipsky, E. M. and Robinson, A. L.: Effects of Dilution on Fine Particle Mass and Partitioning of Semivolatile Organics in Diesel Exhaust and Wood Smoke, Environ. Sci. Technol., 40, 155-162, doi:10.1021/es050319p, 2006.

Liu, Z. G., Berg, D. R., Swor, T. A., and Schauer, J. J.: Comparative Analysis on the Effects of Diesel Particulate Filter and Selective Catalytic Reduction Systems on a Wide Spectrum of Chemical Species Emissions, Environ. Sci. Technol., 42, 6080-6085, doi:10.1021/es8004046, 2008. 
Liu, Z. G., Berg, D. R., Vasys, V. N., Dettmann, M. E., Zielinska, B., and Schauer, J. J.: Analysis of C1, C2, and C10 through C33 particle-phase and semi-volatile organic compound emissions from heavy-duty diesel engines, Atmos. Environ., 44, 11081115, doi:10.1016/j.atmosenv.2009.11.036, 2010.

Matsunaga, A., and Ziemann, P. J.: Gas-Wall Partitioning of Organic Compounds in a Teflon Film Chamber and Potential Effects on Reaction Product and Aerosol Yield Measurements, Aerosol Sci. Technol., 44, 881-892, doi:10.1080/02786826.2010.501044, 2010.

Matti Maricq, M.: Chemical characterization of particulate emissions from diesel engines: A review, J. Aerosol Sci., 38, 10791118, doi:10.1016/j.jaerosci.2007.08.001, 2007.

May, A. A., Presto, A. A., Hennigan, C. J., Nguyen, N. T., Gordon, T. D., and Robinson, A. L.: Gas-particle partitioning of primary organic aerosol emissions: (1) Gasoline vehicle exhaust, Atmos. Environ., 77, 128-139, doi:10.1016/j.atmosenv.2013.04.060, 2013a.

May, A. A., Presto, A. A., Hennigan, C. J., Nguyen, N. T., Gordon, T. D., and Robinson, A. L.: Gas-Particle Partitioning of Primary Organic Aerosol Emissions: (2) Diesel Vehicles, Environ. Sci. Technol., 47, 8288-8296, doi:10.1021/es400782j, 2013b.

May, A. A., Nguyen, N. T., Presto, A. A., Gordon, T. D., Lipsky, E. M., Karve, M., Gutierrez, A., Robertson, W. H., Zhang, M., Chang, O., Chen, S., Cicero-Fernandez, P., Fuentes, M., Huang, S., Ling, R., Long, J., Maddox, C., Massetti, J., McCauley, E., Na, K., Pang, Y., Rieger, P., Sax, T., Truong, T., Vo, T., Chattopadhyay, S., Maldonado, H., Maricq, M. M., and Robinson, A. L.: Gas- and particle-phase primary emissions from in-use, onroad gasoline and diesel vehicles, Atmos. Environ., 88, 247-260, doi:10.1016/j.atmosenv.2014.01.046, 2014.

McMurry, P. H. and Grosjean, D.: Gas and aerosol wall losses in Teflon film smog chambers, Environ. Sci. Technol., 19, 11761182, doi:10.1021/es00142a006, 1985.

Millstein, D. E. and Harley, R. A.: Effects of Retrofitting Emission Control Systems on In-Use Heavy Diesel Vehicles, Environ. Sci. Technol., 44, 5042-5048, doi:10.1021/es1006669, 2010.

Miracolo, M., Hennigan, C., Ranjan, M., Nguyen, N., Gordon, T., Lipsky, E., Presto, A., Donahue, N., and Robinson, A.: Secondary aerosol formation from photochemical aging of aircraft exhaust in a smog chamber, Atmos. Chem. Phys., 11, 41354147, doi:10.5194/acp-11-4135-2011, 2011.

Miracolo, M. A., Presto, A. A., Lambe, A. T., Hennigan, C. J., Donahue, N. M., Kroll, J. H., Worsnop, D. R., and Robinson, A. L.: Photo-Oxidation of Low-Volatility Organics Found in Motor Vehicle Emissions: Production and Chemical Evolution of Organic Aerosol Mass, Environ. Sci. Technol., 44, 1638-1643, doi:10.1021/es902635c, 2010.

Miracolo, M. A., Drozd, G. T., Jathar, S. H., Presto, A. A., Lipsky, E. M., Corporan, E., and Robinson, A. L.: Fuel Composition and Secondary Organic Aerosol Formation: Gas-Turbine Exhaust and Alternative Aviation Fuels, Environ. Sci. Technol., 46, 8493-8501, doi:10.1021/es300350c, 2012.

Nakao, S., Shrivastava, M., Nguyen, A., Jung, H., and Cocker III, D.: Interpretation of Secondary Organic Aerosol Formation from Diesel Exhaust Photooxidation in an Environmental Chamber, Aerosol Sci. Technol., 45, 964-972, 2011.

Ng, N., Kroll, J., Chan, A., Chhabra, P., Flagan, R., and Seinfeld, J.: Secondary organic aerosol formation from $\mathrm{m}$-xylene, toluene, and benzene, Atmos. Chem. Phys., 7, 3909-3922, doi:10.5194/acp-7-3909-2007, 2007.

Ntziachristos, L., Samaras, Z., Zervas, E., and Dorlhène, P.: Effects of a catalysed and an additized particle filter on the emissions of a diesel passenger car operating on low sulphur fuels, Atmos. Environ., 39, 4925-4936, doi:10.1016/j.atmosenv.2005.04.040, 2005.

Odum, J. R., Hoffmann, T., Bowman, F., Collins, D., Flagan, R. C., and Seinfeld, J. H.: Gas/Particle Partitioning and Secondary Organic Aerosol Yields, Environ. Sci. Technol., 30, 2580-2585, doi:10.1021/es950943 +, 1996.

Odum, J. R., Jungkamp, T., Griffin, R., Flagan, R. C., and Seinfeld, J. H.: The atmospheric aerosol-forming potential of whole gasoline vapor, Science, 276, 96-99, doi:10.1126/science.276.5309.96, 1997.

Pisano, J., Durbin, T., Karavalakis, G., Collins, T., Huai, T., Ayala, A., Cicero-Fernandez, P., Zhang, M., Gutierrez, A., Huo, D., and Vo, T.: Characterization of PM and PM Instruments for High Emitting Light-Duty Gasoline Vehicles, SAE paper, 01, 2011.

Platt, S. M., El Haddad, I., Zardini, A. A., Clairotte, M., Astorga, C., Wolf, R., Slowik, J. G., Temime-Roussel, B., Marchand, N., Ježek, I., Drinovec, L., Močnik, G., Möhler, O., Richter, R., Barmet, P., Bianchi, F., Baltensperger, U., and Prévôt, A. S. H.: Secondary organic aerosol formation from gasoline vehicle emissions in a new mobile environmental reaction chamber, Atmos. Chem. Phys., 13, 9141-9158, doi:10.5194/acp-13-91412013, 2013.

Presto, A. A., Huff Hartz, K. E., and Donahue, N. M.: Secondary Organic Aerosol Production from Terpene Ozonolysis. 2. Effect of $\mathrm{NO}_{\mathrm{x}}$ Concentration, Environ. Sci. Technol., 39, 7046-7054, doi:10.1021/es050400s, 2005a.

Presto, A. A., Huff Hartz, K. E., and Donahue, N. M.: Secondary Organic Aerosol Production from Terpene Ozonolysis. 1. Effect of UV Radiation, Environ. Sci. Technol., 39, 7036-7045, doi:10.1021/es050174m, 2005b.

Presto, A. A., Miracolo, M. A., Donahue, N. M., and Robinson, A. L.: Secondary Organic Aerosol Formation from High- $\mathrm{NO}_{\mathrm{x}}$ Photo-Oxidation of Low Volatility Precursors: n-Alkanes, Environ. Sci. Technol., 44, 2029-2034, doi:10.1021/es903712r, 2010.

Presto, A. A., Nguyen, N. T., Ranjan, M., Reeder, A. J., Lipsky, E. M., Hennigan, C. J., Miracolo, M. A., Riemer, D. D., and Robinson, A. L.: Fine particle and organic vapor emissions from staged tests of an in-use aircraft engine, Atmos. Environ., 45, 3603-3612, 2011.

Ratcliff, M. A., Dane, A. J., Williams, A., Ireland, J., Luecke, J., McCormick, R. L., and Voorhees, K. J.: Diesel Particle Filter and Fuel Effects on Heavy-Duty Diesel Engine Emissions, Environ. Sci. Technol., 44, 8343-8349, doi:10.1021/es1008032, 2010.

Robinson, A. L., Donahue, N. M., Shrivastava, M. K., Weitkamp, E. A., Sage, A. M., Grieshop, A. P., Lane, T. E., Pierce, J. R., and Pandis, S. N.: Rethinking organic aerosols: Semivolatile emissions and photochemical aging, Science, 315, 1259-1262, doi:10.1126/science.1133061, 2007.

Samy, S. and Zielinska, B.: Secondary organic aerosol production from modern diesel engine emissions, Atmos. Chem. Phys., 10, 609-625, doi:10.5194/acp-10-609-2010, 2010.

Schauer, J. J., Kleeman, M. J., Cass, G. R., and Simoneit, B. R. T.: Measurement of Emissions from Air Pollution Sources. 2. C1 through C30 Organic Compounds from Medium 
Duty Diesel Trucks, Environ. Sci. Technol., 33, 1578-1587, doi:10.1021/es980081n, 1999.

Seinfeld, J. and Pandis, S.: Atmospheric Chemistry and Physics: From air pollution to climate change, John Wiley \& Sons, New York, p. 208, 2006.

Song, C., Na, K., and Cocker, D. R.: Impact of the Hydrocarbon to $\mathrm{NO}_{\mathrm{x}}$ Ratio on Secondary Organic Aerosol Formation, Environ. Sci. Technol., 39, 3143-3149, doi:10.1021/es0493244, 2005.

Stone, E. A., Zhou, J., Snyder, D. C., Rutter, A. P., Mieritz, M., and Schauer, J. J.: A Comparison of Summertime Secondary Organic Aerosol Source Contributions at Contrasting Urban Locations, Environ. Sci. Technol., 43, 3448-3454, doi:10.1021/es8025209, 2009.

Subramanian, R., Donahue, N. M., Bernardo-Bricker, A., Rogge, W. F., and Robinson, A. L.: Insights into the primary-secondary and regional-local contributions to organic aerosol and $\mathrm{PM}_{2.5}$ mass in Pittsburgh, Pennsylvania, Atmos. Environ., 41, 74147433, doi:10.1016/j.atmosenv.2007.05.058, 2007.

Tkacik, D. S., Presto, A. A., Donahue, N. M., and Robinson, A. L.: Secondary Organic Aerosol Formation from Intermediate-Volatility Organic Compounds: Cyclic, Linear, and Branched Alkanes, Environ. Sci. Technol., 46, 8773-8781, doi:10.1021/es301112c, 2012.

Vaaraslahti, K., Virtanen, A., Ristimäki, J., and Keskinen, J.: Nucleation Mode Formation in Heavy-Duty Diesel Exhaust with and without a Particulate Filter, Environ. Sci. Technol., 38, 4884-4890, doi:10.1021/es0353255, 2004.
Volkamer, R., Jimenez, J. L., San Martini, F., Dzepina, K., Zhang, Q., Salcedo, D., Molina, L. T., Worsnop, D. R., and Molina, M. J.: Secondary organic aerosol formation from anthropogenic air pollution: Rapid and higher than expected, Geophys. Res. Lett., 33, L17811, doi:10.1029/2006GL026899, 2006.

Vutukuru, S., Griffin, R. J., and Dabdub, D.: Simulation and analysis of secondary organic aerosol dynamics in the South Coast Air Basin of California, J. Geophys. Res, 111, D10S12, doi:10.1029/2005JD006139, 2006.

Warner, J. R., Dobson, D., and Cavataio, G.: A Study of Active and Passive Regeneration Using Laboratory Generated Soot on a Variety of SiC Diesel Particulate Filter Formulations, SAE International Journal of Fuels and Lubricants, 3, 149-164, 2010.

Weitkamp, E., Sage, A., Pierce, J., Donahue, N., and Robinson, A.: Organic Aerosol Formation from Photochemical Oxidation of Diesel Exhaust in a Smog Chamber, Environ. Sci. Technol., 41, 6969-6975, 2007.

Yang, J., Stewart, M., Maupin, G., Herling, D., and Zelenyuk, A.: Single wall diesel particulate filter (DPF) filtration efficiency studies using laboratory generated particles, Chem. Eng. Sci., 64, 1625-1634, doi:10.1016/j.ces.2008.12.011, 2009.

Zhen, F., Clark, N. N., Bedick, C. R., Gautam, M., Wayne, W. S., Thompson, G. J., and Lyons, D. W.: Development of a Heavy Heavy-Duty Diesel Engine Schedule for Representative Measurement of Emissions, J. Air Waste Manage. Assoc., 59, 950959, doi:10.3155/1047-3289.59.8.950, 2009. 